\title{
Antcin K, a Triterpenoid Compound from Antrodia camphorata, Displays Antidiabetic and Antihyperlipidemic Effects via Glucose Transporter 4 and AMP-Activated Protein Kinase Phosphorylation in Muscles
}

\author{
Yueh-Hsiung Kuo, ${ }^{1}$ Cheng-Hsiu Lin, ${ }^{2}$ Chun-Ching Shih, ${ }^{3}$ and Chang-Syun Yang ${ }^{1}$ \\ ${ }^{1}$ Department of Chinese Pharmaceutical Sciences and Chinese Medicine Resources, China Medical University, Taichung 40402, Taiwan \\ ${ }^{2}$ Department of Internal Medicine, Fengyuan Hospital, Ministry of Health and Welfare, Fengyuan District, Taichung 42055, Taiwan \\ ${ }^{3}$ Graduate Institute of Pharmaceutical Science and Technology, College of Health Science, Central Taiwan University of Science and \\ Technology, No. 666 Buzih Road, Beitun District, Taichung 40601, Taiwan
}

Correspondence should be addressed to Chun-Ching Shih; ccshih@ctust.edu.tw

Received 4 January 2016; Revised 26 February 2016; Accepted 16 March 2016

Academic Editor: Menaka C. Thounaojam

Copyright (c) 2016 Yueh-Hsiung Kuo et al. This is an open access article distributed under the Creative Commons Attribution License, which permits unrestricted use, distribution, and reproduction in any medium, provided the original work is properly cited.

\begin{abstract}
The purpose of this study was to screen firstly the potential effects of antcin $\mathrm{K}$ (AnK), the main constituent of the fruiting body of Antrodia camphorata, in vitro and further evaluate the activities and mechanisms in high-fat-diet- (HFD-) induced mice. Following 8-week HFD-induction, mice were treated with AnK, fenofibrate (Feno), metformin (Metf), or vehicle for 4 weeks afterward. In $\mathrm{C} 2 \mathrm{C} 12$ myotube cells, the membrane GLUT4 and phospho-Akt expressions were higher in insulin and AnK-treated groups than in the control group. It was observed that AnK-treated mice significantly lowered blood glucose, triglyceride, total cholesterol, and leptin levels in AnK-treated groups. Of interest, AnK at $40 \mathrm{mg} / \mathrm{kg} /$ day dosage displayed both antihyperglycemic effect comparable to Metf $(300 \mathrm{mg} / \mathrm{kg} / \mathrm{day})$ and antihypertriglyceridemic effect comparable to Feno $(250 \mathrm{mg} / \mathrm{kg} / \mathrm{day})$. The combination of significantly increased skeletal muscular membrane expression levels of glucose transporter 4 (GLUT4) but decreased hepatic glucose-6phosphatase (G6 Pase) mRNA levels by AnK thus contributed to a decrease in blood glucose levels. Furthermore, AnK enhanced phosphorylation of AMP-activated protein kinase (phospho-AMPK) expressions in the muscle and liver. Moreover, AnK treatment exhibited inhibition of hepatic fatty acid synthase (FAS) but enhancement of fatty acid oxidation peroxisome proliferator-activated receptor $\alpha(\mathrm{PPAR} \alpha)$ expression coincident with reduced sterol response element binding protein-lc (SREBP-1c) mRNA levels in the liver may contribute to decreased plasma triglycerides, hepatic steatosis, and total cholesterol levels. The present findings indicate that AnK displays an advantageous therapeutic potential for the management of type 2 diabetes and hyperlipidemia.
\end{abstract}

\section{Introduction}

Diabetes mellitus hardly occurs in isolation but is most often part of an array of metabolic abnormalities that includes insulin resistance, hyperinsulinemia, and hypertriglyceridemia. The population of type 2 diabetes prevalence by 2025 will reach approximately 300 million [1]. Pathogenesis of type 2 diabetes has been proposed to display more than $90 \%$ of all diabetes mellitus patients [2]. Type 2 diabetes mellitus has revealed mechanisms of insulin resistance that target either impairs in $\beta$-cell function or insulin insensitive action at adipose tissue, skeletal muscle, or liver tissues.

Antrodia camphorata (Polyporaceae, Aphyllophorales) is edible as a folk remedy in the treatment of a variety of diseases in Taiwan. It is rare and expensive because it grows only on the inner heartwood wall of the endemic evergreen Cinnamomum kanehirai. The mycelia, filtrate of broth, and fruiting body of $A$. camphorata exhibit numerous physiological 
functions [3]. The fruiting body of $A$. camphorata consisted of terpenoids, such as antcins (A, B, and C), zhankuic acids (A, B, C, D, and E), $15 \alpha$-acetyl-dehydrosulphurenic acid, dehydroeburicoic acid and dehydrosulphurenic acid, antcin $\mathrm{E}$ and $\mathrm{F}$, methyl antcinate $\mathrm{G}$ and methyl antcinate $\mathrm{H}$, and eburicoic acid. The solid culture of fruiting body and the filtrate in submerged culture have been shown to have hepatoprotective effects and antioxidant activities $[4,5]$. Previous study had demonstrated that, in terms of in vivo metabolism, 13 terpenoids in A. camphorata were determined by using $\mathrm{LC} / \mathrm{MS} / \mathrm{MS}$ in rats plasma after oral administration, and plasma concentrations of ergostanoids were much higher than lanostanoids, and the ergostanoids underwent reduction and hydroxylation reactions in vivo [6]. Their mean residence time (MRT) ranged from 3 to $6 \mathrm{hr}$, and the lanostanoids were not active to metabolic reactions and were slowly eliminated

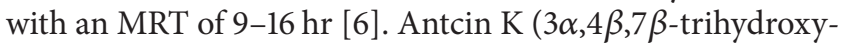
$4 \alpha$-methylergosta-8,24(28)-dien-11-on-26-oic acid, 2; AnK) (Figure 1), an active triterpenoid from the fruiting bodies of basswood cultivated A. cinnamomea, could induce apoptotic cell death in human liver cancer Hep3B cells [7]. Antcin $\mathrm{K}$ isolated from ethanol extracts of wild fruiting body has shown concentration-dependent (1-25 Mm) antiinflammatory effects (by modulation of leukocyte activity and inhibition of ROS) induced by fMLP and TPA in human neutrophils $[8,9]$. Our recent studies demonstrated that ergostatrien-3 $\beta$-ol and dehydroeburicoic acid from $A$. camphorata exhibited an excellent antihyperglycemic and antihyperlipidemic activity [10, 11]. Nevertheless, the effects of antcin $\mathrm{K}$, the main constituent of the fruiting body of $A$. camphorata, on diabetes and dyslipidemia are still unknown in vitro and in diet-induced diabetic rodents.

The glucose transporter 4 (GLUT4) has been regarded as a vital determinant of blood glucose homeostasis [12]. The elevated glucose levels, after huge caloric ingestions, are rapidly returned to normal. Insulin stimulates or contraction causes glucose uptake via eliciting translocation of GLUT4 from intracellular sites to the membrane [13, 14]. Levels of insulin-induced GLUT4 translocation in skeletal muscle of type 2 diabetic patients are markedly decreased [15]. Therefore, the improvement of GLUT4 levels or induced translocation may accelerate drug development. Peripheral glucose uptake into membrane of skeletal muscle could be promoted by two pathways including insulin-dependent mechanisms leading to Akt/PKB activation and contractionregulated stimulation $[16,17]$ or hypoxia-regulated AMPK activation $[17,18]$. AMPK play a dominant role in glucose and lipid metabolism. Since dysregulation of glucose and lipid catabolism in type 2 diabetes, AMPK activators would be promising therapies [19].

Metformin is used in the clinics as an antidiabetic drug in the management of type 2 diabetes [19] and it activates AMPK in both hepatocyte and skeletal muscle $[19,20]$.

Peroxisome proliferator-activated receptor $\alpha(\operatorname{PPAR} \alpha)$ plays a key role in regulation of lipid metabolism [21] and reduces circulating triglyceride (TG) concentrations via regulated numerous genes associated with lipogenic and fatty acids oxidation [22]. Fenofibrate is one of PPAR $\alpha$ agonists

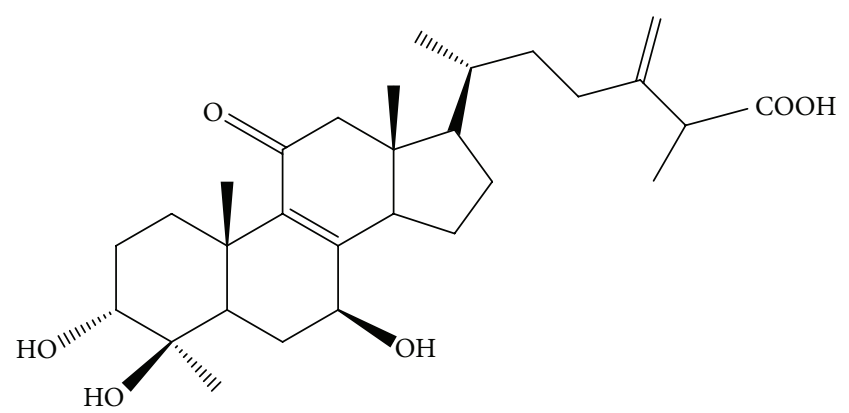

FIgURE 1: Chemical structure of antcin K (AnK).

and has been used in the treatment of hypertriglyceridemia $[23,24]$.

The high-fat diet- (HFD-) fed C57BL/6J mouse could induce early type 2 diabetes and markedly increased adipose weights and produced resistance to insulin and increases in blood glucose, total cholesterol (TC), and TG levels [25-27]. Thus, this model was chosen to investigate both mechanistic activities and as a tool for developing novel therapeutic interventions [25]. Phosphorylation of $\mathrm{Thr}^{172}$ of $\alpha$ subunits is essential for AMPK activity [28]. This study was to screen firstly the potential effects of AnK in vitro and further to investigate the hypothesis that AnK could display the beneficial metabolic effects including antidiabetic and hypolipidemic effects by modulation of GLUT4 protein expression and activation of AMPK as compared with clinical drugs such as Metf and Feno; moreover, the targeted gene expressions were determined including PPAR $\alpha$ and fatty acid synthase (FAS) from the peripheral tissues of HFD-fed mice by the AnK treatment.

\section{Materials and Methods}

2.1. Chemicals. Antibodies of GLUT4 (number sc-79838) were obtained from Santa Cruz Biotech (Santa Cruz, CA, USA); phospho-AMPK (Thr ${ }^{172}$ ), PPAR $\alpha$ (number ab8934), and PPAR $\gamma$ (number ab45036) were purchased from Abcam Inc. (Cambridge, MA, USA); FAS (number 3180), phosphoAkt (Ser473) (number 4060), total-AMPK $\left(\mathrm{Thr}^{172}\right.$ ), and $\beta$ actin (number 4970) were from Cell Signaling Technology (Danvers, MA, USA). Secondary antibody anti-rabbit was from Jackson ImmunoRes. Lab., Inc. (West Grove, PA, USA).

2.2. Determination of the Active Compound. The fruiting body of A. camphorata was purchased from the Balay Biotechnology Corporation, Hsinchu City, Taiwan. A voucher specimen (CMPC393) was deposited at and identified by China Medical University. The fruiting bodies of AC $(3.0 \mathrm{~kg})$ were extracted three times with methanol and followed by chromatography using 50\% ethyl acetate and 50\% hexane. The procedure was as in a previously described report [29]. The purity of AnK is above $99 \%$. Analytical instrument is the HPLC, SHIMADZU LC 20-A; the HPLC Column, TOSOH TSKgel DS-80Ts, and analytical condition, $100 \% \mathrm{MeOH}$. 
2.3. Cell Culture. C2C12 skeletal myoblasts (ATCC, CRL1772) were employed and performed as a previous report [11].

2.4. Detection of Expression Levels of Membrane GLUT4 and Phosphorylation of Akt (Ser473) In Vitro. The procedure was performed as a previous description [11, 30, 31]. Differentiated $\mathrm{C} 2 \mathrm{C} 12$ cells were serum-starved in DMEM/BSA prior to incubation either with test compounds (AnK at 1, 5, 10, and $25 \mu \mathrm{g} / \mathrm{mL}$ ) or with vehicle for $30 \mathrm{~min}$ or with $100 \mathrm{nM}$ insulin for $25 \mathrm{~min}$, as previously described [32]. The homogenates were centrifuged and the pellet was resuspended and performed within membrane; protein concentration was analyzed via BCA assay (Pierce), and equal amounts of protein were then diluted four times in SDS sample buffer and subjected to SDS PAGE and were detected by Western blotting with antibodies specific for Akt, phospho-Akt Ser473, and GLUT4; and the analysis of density blotting was as in a previous report [11].

2.5. Animals and Treatments. The part of animal studies was performed under the guidelines of the Institutional Animal Care and Use Committee (12 March 2015). The C57BL/6J mice (male) aged 4 weeks (total amount $=63$ ) were obtained from the National Laboratory Animal Breeding Center. All rodents were haphazardly partitioned to control (CON) group (control diet) (Diet 12450B, Research Diets, Inc.; lowfat diet) $(n=9)$ and high-fat diet (HFD) (Diet 12451, Research Diets, Inc.) group [10, 33, 34]. The low-fat diet was composed of protein $20 \%$, carbohydrate $70 \%$, and fat $10 \%$, whereas highfat diet was composed of protein $20 \%$, carbohydrate $35 \%$, and fat $45 \%$ (of total energy, $\% \mathrm{kcal}$ ). The CON mice were on the control diet, and the HFD mice were on $45 \%$ HFD for 12 weeks [33]. The control diet or HFD is comprised of $10 \%$ fat or $45 \%$ fat, respectively. After HFD-induction for 8 weeks, the HFD-fed group (total amounts: 54 mice) was again divided into 6 groups ( $n=9$, per group) as follows: treatment with AnK (including AnK1: 10, AnK2: 20, and AnK3: $40 \mathrm{mg} / \mathrm{kg} / \mathrm{day}$ bw), or fenofibrate (Feno: $0.25 \mathrm{~g} / \mathrm{kg} / \mathrm{day}$ bw, Sigma Chemical Co.), or metformin ( $0.3 \mathrm{~g} / \mathrm{kg} /$ day bw), or vehicle with oral gavage one time every day for 28 days, and the $\mathrm{CON}$ and high-fat control (HF) groups were given only vehicle $[10,33]$. After administration of AnK, Feno, or Metf for 4 weeks, the mice (12 h fasting) were sacrificed and peripheral tissues were weighed. Parts of tissues were immediately stored at $-80^{\circ} \mathrm{C}$ for targeted genes analysis. Blood glucose analysis and biochemical parameters (including TG, TC, and FFA), adipocytokine (including insulin, adiponectin, and leptin) levels, and metabolic parameters including body weight, weight gain, and food intake were performed as previous procedures $[10,11,33]$.

\subsection{Assessment of Blood Glucose and Biochemical Parameters.} Blood sample was obtained from the retro-orbital sinus of $12 \mathrm{~h}$ fasting mice. Blood glucose level (by the glucose oxidase method); plasma TG, TC, and free fatty acids level (using commercial assay kits); and insulin, leptin, and adiponectin level (by enzyme-linked immunosorbent assay (ELISA) kits) were measured as previous reports [11,33, 35, 36].
2.7. Histopathology Examination. Parts of visceral adipose and liver specimen were measured and pictures were taken as previous reports $[11,33,36]$.

2.8. Analysis of Liver Lipids. This procedure was performed as in previous reports [37].

2.9. Relative Quantization of $m R N A$ Indicating Gene Levels and Western Blotting. These procedures of relative quantization of mRNA (the primers are described in Table 1) and immunoblots in the measurement of skeletal muscular GLUT4, phospho-AMPK $\left(\mathrm{Thr}^{172}\right) /$ total-AMPK $\left(\mathrm{Thr}^{172}\right)$, or phospho-Akt (Ser473)/total-Akt (Ser473) proteins from the muscle and liver of mice were performed as previous procedures elsewhere [10, 11, 33, 35, 36]. PPAR $\alpha$ and FAS proteins were performed from the liver tissue and PPAR $\gamma$ and FAS proteins from the adipose tissue of mice. Skeletal muscle from mice was subjected to GLUT4 expression level analysis. Total membrane fraction was measured; and the expression levels of GLUT4, phospho-AMPK, and total-AMPK were determined by Western blotting as in described reports $[10$, $11,33,35,36]$.

2.10. Statistics. Results present means and standard error. Comparisons among groups were using ANOVA and coupled with Dunnett's tests. $P$ values less than 0.05 were regarded as statistically significant differences.

\section{Results}

3.1. Membrane GLUT4 and Akt Phosphorylation Expression In Vitro. The membrane GLUT4 expressions were higher in the insulin- and AnK-treated $(5,10$, and $25 \mu \mathrm{g} / \mathrm{mL})$ groups than in the CON group. The phospho-Akt (Ser473)/total-Akt expressions were higher in the insulin- and AnK-treated (10 and $25 \mu \mathrm{g} / \mathrm{mL}$ ) groups than in CON group (Figures 2(a) and 2(b)).

3.2. Metabolic Parameters. At the beginning, the average body weights of all mice were $20.05 \pm 0.13 \mathrm{~g}$. At the end, body weight and body weight gain were markedly enhanced in HFD-induced mice (Table 2). AnK2-, AnK3-, or Feno-treated mice had decreased body weight, while AnK1-, AnK2-, AnK3-, Feno-, or Metf- treated groups had decreased body weight gain. The HF mice consume less food intake than CON mice (Table 2). No difference was found in food intake between AnK-, Feno-, or Metf-treated groups and HF group. Feeding a HFD displayed increases in absolute epididymal, mesenteric, retroperitoneal white adipose tissue (WAT) and visceral fat weights (Table 2). The AnK1-, AnK2-, AnK3-, Feno-, or Metf-treated groups reduced epididymal, retroperitoneal WAT, mesenteric WAT, and visceral fat weights. Fenotreated mice showed a decrease in brown adipose tissue (BAT) weights, but increased weights of the liver (Table 2).

3.3. Fasting Blood Glucose Levels, Biochemical Parameters, Adipocytokine Levels, and Liver Lipids. It is evident that hyperglycemia has been observed after 12 weeks of HFD 
TABle 1: Primers used in this study.

\begin{tabular}{|c|c|c|c|c|}
\hline Gene & Accession number & Forward primer and reverse primer & PCR product (bp) & Annealing temperature $\left({ }^{\circ} \mathrm{C}\right)$ \\
\hline \multicolumn{5}{|c|}{ Liver } \\
\hline G6 Pase & NM_008061.3 & $\begin{array}{l}\text { F: GAACAACTAAAGCCTCTGAAAC } \\
\text { R: TTGCTCGATACATAAAACACTC }\end{array}$ & 350 & 50 \\
\hline SREBPlc & NM_011480 & $\begin{array}{l}\text { F: GGCTGTTGTCTACCATAAGC } \\
\text { R: AGGAAGAAACGTGTCAAGAA }\end{array}$ & 219 & 48 \\
\hline DGAT2 & NM_026384.3 & $\begin{array}{l}\text { F: AGTGGCAATGCTATCATCATCGT } \\
\text { R: AAGGAATAAGTGGGAACCAGATCA }\end{array}$ & 149 & 50 \\
\hline apo C-III & NM_023114.3 & $\begin{array}{l}\text { F: CAGTTTTATCCCTAGAAGCA } \\
\text { R: TCTCACGACTCAATAGCTG }\end{array}$ & 349 & 47 \\
\hline SREBP2 & AF289715.2 & $\begin{array}{l}\text { F: ATATCATTGAAAAGCGCTAC } \\
\text { R: ATTTTCAAGTCCACATCACT }\end{array}$ & 256 & 48 \\
\hline $\operatorname{PPAR} \alpha$ & NM_011144 & $\begin{array}{l}\text { F: ACCTCTGTTCATGTCAGACC } \\
\text { R: ATAACCACAGACCAACCAAG }\end{array}$ & 352 & 49 \\
\hline $\mathrm{aP} 2$ & NM_024406 & $\begin{array}{l}\text { F: TCACCTGGAAGACAGCTCCT } \\
\text { R: TGCCTGCCACTTTCCTTGT }\end{array}$ & 142 & 52 \\
\hline GAPDH & NM_008084.3 & $\begin{array}{l}\text { F: TGTGTCCGTCGTGGATCTGA } \\
\text { R: CCTGCTTCACCACCTTCTTGA }\end{array}$ & 99 & 55 \\
\hline
\end{tabular}

TABLE 2: Effects of antcin K (AnK) on tissue weight, food intake, and liver lipid.

\begin{tabular}{|c|c|c|c|c|c|c|c|}
\hline $\begin{array}{l}\text { Dose } \\
\text { (mg/kg/day) }\end{array}$ & $\mathrm{CON}$ & $\mathrm{HF}$ & $\begin{array}{c}\mathrm{HF}+\mathrm{AnK} 1 \\
10\end{array}$ & $\begin{array}{c}\mathrm{HF}+\mathrm{AnK} 2 \\
20\end{array}$ & $\begin{array}{c}\mathrm{HF}+\mathrm{AnK} 3 \\
40\end{array}$ & $\begin{array}{c}\mathrm{HF}+\text { Feno } \\
250\end{array}$ & $\begin{array}{c}\mathrm{HF}+\text { Metf } \\
300\end{array}$ \\
\hline \multicolumn{8}{|c|}{ Absolute tissue weight (g) } \\
\hline EWAT & $0.531 \pm 0.052$ & $1.264 \pm 0.147^{\# \# \#}$ & $0.867 \pm 0.065^{* *}$ & $0.841 \pm 0.062^{* *}$ & $0.809 \pm 0.058^{* * *}$ & $0.603 \pm 0.041^{* * *}$ & $0.813 \pm 0.064^{* * *}$ \\
\hline MWAT & $0.278 \pm 0.031$ & $0.439 \pm 0.025^{\# \# \#}$ & $0.349 \pm 0.020^{*}$ & $0.340 \pm 0.013^{*}$ & $0.332 \pm 0.025^{*}$ & $0.247 \pm 0.025^{* * *}$ & $0.270 \pm 0.018^{* * *}$ \\
\hline RWAT & $0.166 \pm 0.021$ & $0.483 \pm 0.064^{\# \# \#}$ & $0.323 \pm 0.039^{*}$ & $0.339 \pm 0.031^{*}$ & $0.306 \pm 0.040^{*}$ & $0.181 \pm 0.020^{* * *}$ & $0.298 \pm 0.027^{* *}$ \\
\hline Visceral fat & $0.697 \pm 0.056$ & $1.747 \pm 0.208^{\# \# \#}$ & $1.190 \pm 0.093^{* *}$ & $1.180 \pm 0.106^{* *}$ & $1.154 \pm 0.096^{* * *}$ & $0.784 \pm 0.052^{* * *}$ & $1.111 \pm 0.077^{* * *}$ \\
\hline Skeletal muscle & $0.308 \pm 0.014$ & $0.412 \pm 0.045$ & $0.395 \pm 0.036$ & $0.364 \pm 0.022$ & $0.364 \pm 0.028$ & $0.428 \pm 0.026$ & $0.380 \pm 0.025$ \\
\hline BAT & $0.158 \pm 0.004$ & $0.224 \pm 0.022^{\#}$ & $0.178 \pm 0.007$ & $0.172 \pm 0.010$ & $0.175 \pm 0.008$ & $0.157 \pm 0.013^{*}$ & $0.220 \pm 0.025$ \\
\hline Liver (g) & $1.003 \pm 0.024$ & $0.987 \pm 0.029$ & $0.946 \pm 0.030$ & $0.888 \pm 0.019$ & $0.883 \pm 0.018$ & $1.700 \pm 0.070^{* * *}$ & $0.908 \pm 0.031$ \\
\hline Spleen (g) & $0.099 \pm 0.006$ & $0.094 \pm 0.004$ & $0.090 \pm 0.003$ & $0.085 \pm 0.003$ & & $0.084 \pm 0.005$ & $0.093 \pm 0.006$ \\
\hline $\begin{array}{l}\text { Final body } \\
\text { weight (g) }\end{array}$ & $27.21 \pm 0.47$ & $30.43 \pm 1.02^{\#}$ & $28.30 \pm 0.61$ & $27.55 \pm 0.72^{*}$ & $27.48 \pm 0.46^{*}$ & $27.55 \pm 0.84^{*}$ & $27.86 \pm 0.72$ \\
\hline $\begin{array}{l}\text { Weight gain } \\
\text { (g) }\end{array}$ & $1.61 \pm 0.15$ & $3.42 \pm 0.24^{\#}$ & $1.39 \pm 0.81^{*}$ & $0.70 \pm 0.86^{* *}$ & $0.58 \pm 0.35^{* *}$ & $0.57 \pm 0.55^{* * *}$ & $0.92 \pm 0.08^{* *}$ \\
\hline $\begin{array}{l}\text { Food intake } \\
\text { (g/day/mouse) }\end{array}$ & $2.34 \pm 0.04$ & $1.99 \pm 0.04^{\# \# \#}$ & $1.95 \pm 0.05$ & $1.92 \pm 0.07$ & $1.98 \pm 0.04$ & $1.99 \pm 0.06$ & $1.89 \pm 0.04$ \\
\hline \multicolumn{8}{|c|}{ Liver lipids } \\
\hline $\begin{array}{l}\text { Total lipid } \\
(\mathrm{mg} / \mathrm{g})\end{array}$ & $53.7 \pm 2.7$ & $95.9 \pm 6.4^{\# \# \#}$ & $73.1 \pm 4.7^{* *}$ & $66.0 \pm 4.8^{* *}$ & $64.5 \pm 5.2^{* *}$ & $64.9 \pm 5.1^{* *}$ & $65.3 \pm 4.9^{* *}$ \\
\hline $\begin{array}{l}\text { Triacylglycerol } \\
(\mu \mathrm{mol} / \mathrm{g})\end{array}$ & $40.6 \pm 3.9$ & $79.3 \pm 6.3^{\# \# \#}$ & $56.3 \pm 4.2^{* *}$ & $45.7 \pm 3.9^{* * *}$ & $45.2 \pm 4.6^{* * *}$ & $47.3 \pm 4.6^{* * *}$ & $45.4 \pm 4.2^{* * *}$ \\
\hline
\end{tabular}

Antcin K (AnK; AnK1, AnK2, and AnK3, 10, 20, and 40 mg/kg body wt); fenofibrate (Feno, $250 \mathrm{mg} / \mathrm{kg}$ body wt); metformin (Metf, $300 \mathrm{mg} / \mathrm{kg}$ body wt); BAT, brown adipose tissue; skeletal muscle included quadriceps muscle, which contains four parts, rectus femoris, vastus intermedius, vastus lateralis, and vastus medialis. All values are means $\pm \mathrm{SE}(n=9) .{ }^{\#} P<0.05$ and ${ }^{\# \# \#} P<0.001$ compared with the control (CON) group; ${ }^{*} P<0.05,{ }^{* *} P<0.01$, and ${ }^{* * *} P<0.001$ compared with the high-fat plus vehicle (distilled water) (HF) group. Epididymal white adipose tissue (epididymal WAT; EWAT), retroperitoneal WAT (RWAT), and mesenteric WAT (MWAT). Visceral fat represented epididymal WAT plus retroperitoneal WAT.

treatment $(P<0.001)$. Treatment with AnK1, AnK2, AnK3, Feno, and Metf markedly lowered glucose levels in blood (Figure 3(a)). HFD increased the levels of circulating TG, total cholesterol (TC), and free fatty acid (Figures 3(b) and 3(c) and Table 2). The AnK1-, AnK2-, AnK3-, Feno-, or Metf-treated mice had decreased TG, TC, and FFA levels.
Plasma insulin and leptin concentrations were higher, but adiponectin levels were lower in the HF group than in the CON group. The AnK1-, AnK2-, AnK3-, Feno-, and Metftreated mice had effectively reduced plasma leptin, insulin, and FFA concentrations but markedly enhanced adiponectin levels (Figures 3(d), 3(e), 3(f), and 3(g)). HFD enhanced 


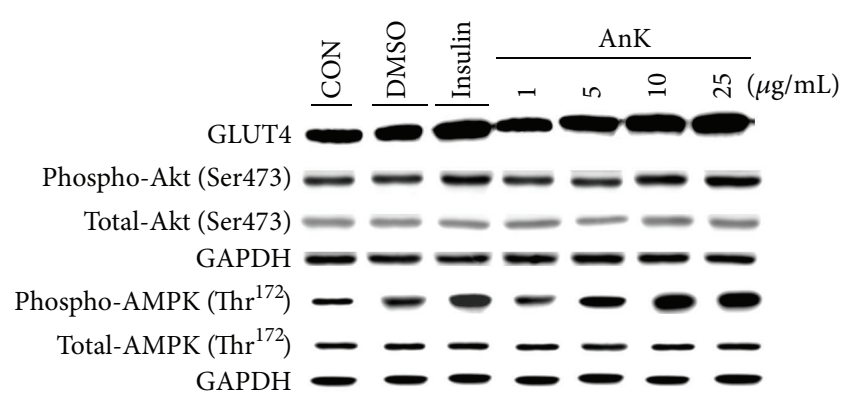

(a)

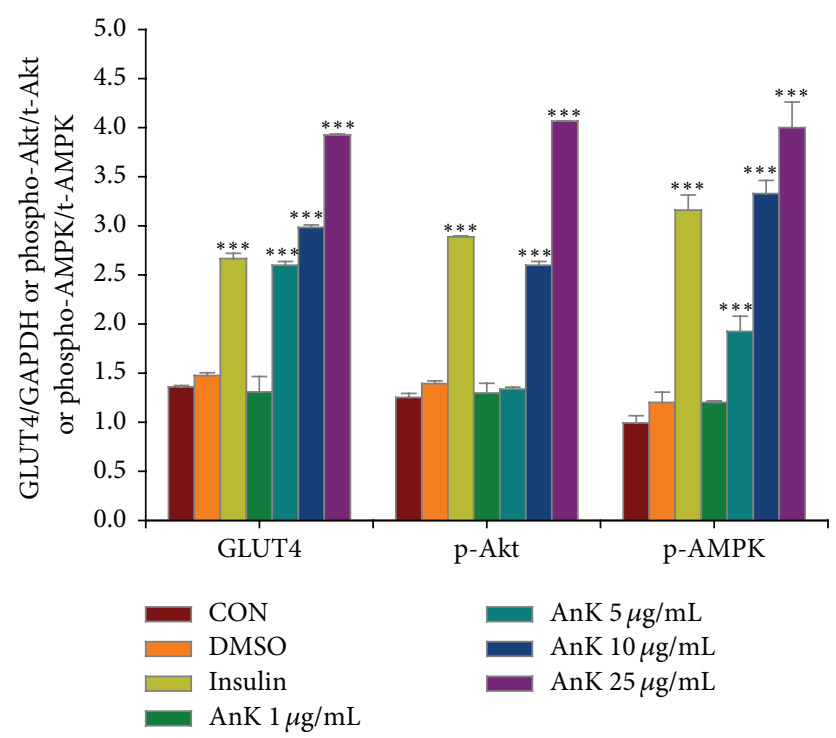

(b)

Figure 2: Effect of antcin K (AnK) on GLUT4, phospho-Akt/total$\mathrm{Akt}$, and phospho-AMPK/total-AMPK in vitro. C2C12 myoblasts cells were treated with AnK compounds as described in the experimental procedures and equal amounts of lysates were resolved by SDS PAGE and blotted for GLUT4, Akt, phospho-Akt (Ser473), AMPK, and phospho-AMPK ( $\mathrm{Thr}^{172}$ ). (a) Representative blots for AnK in C2C12 myoblasts cells; (b) quantification of the GLUT4 protein contents and the ratio of phospho-Akt to total-Akt and phospho-AMPK to total-AMPK. All values are means \pm SE. ${ }^{* * *} P<$ 0.001 compared with the control group.

the levels of liver total lipids and triacylglycerol, and AnK1-, AnK2-, AnK3-, Feno-, or Metf-treated mice had decreased hepatic total lipid and triacylglycerol levels (Table 2).

3.4. Histopathology Examination. HFD caused adipocytes hypertrophy (the following data were calculated average areas: the CON mice, $6044.4 \pm 359.1 \mu \mathrm{m}^{2}$; the HF group, $10142.9 \pm 428.1)$ and following treatment with AnK1 $\left(6548.6 \pm 214.7 \mu \mathrm{m}^{2}\right)$, AnK2 $\left(6483.8 \pm 319.8 \mu \mathrm{m}^{2}\right)$, AnK3 $\left(5670.8 \pm 281.6 \mu \mathrm{m}^{2}\right)$, Feno $\left(6304.2 \pm 316.9 \mu \mathrm{m}^{2}\right)$, or Metf $\left(5873.7 \pm 345.1 \mu \mathrm{m}^{2}\right)$ displayed less hypertrophy (Figure 4(a)). On the basis of a previous study [38], the designation of histological hepatocellular ballooning findings is comprised of grade 0 , none; grade 1, few cells; grade 2, many cells. As shown in Figure 4(b), HFD induced the ballooning of hepatocyte (mean score, $1.9 \pm 0.1$ ) as compared with the CON group (0) in liver tissue. Administration of AnK1 (0.7 \pm 0.2$)$, AnK2 $(0.5 \pm 0.2)$, AnK3 (0.4 \pm 0.2$)$, Feno (0.5 \pm 0.1$)$, or Metf $(0.7 \pm 0.2)$ decreased the ballooning as compared with the HF group.

3.5. Hepatic Targeted Gene mRNA Levels. HFD elicits increases in G6 Pase, acyl-coenzyme A: diacylglycerol acyltransferase 2 (DGAT 2), SREBP1c, aP2, apolipoprotein CIII (apo CIII), and SREBP2 mRNA levels. The AnK1-, AnK2-, AnK3-, Feno-, or Metf-treated mice had decreased mRNA levels of G6 Pase, DGAT2, SREBP1c, aP2, apo CIII, and SREBP2 mRNA levels but increased PPAR $\alpha$ mRNA levels (Figure 5).

3.6. Targeted Protein Expression Levels in Different Tissues. HFD induced decreases in protein expression levels of skeletal muscular membrane GLUT4 $(P<0.001)$. AnK1-, AnK2-, AnK3-, Metf-, or Feno-treated groups enhanced membrane GLUT4 expressions. HFD-induced mice had decreased expression levels of phospho-AMPK/total-AMPK or phospho-Akt/total-Akt in both muscle and the liver, which were markedly enhanced in the AnK1-, AnK2-, AnK3-, Metf-, or Feno-treated mice (Figure 6). HFD-fed mice had decreased liver PPAR $\alpha$ expressions, but increased in FAS levels. Treatment with AnK1, AnK2, AnK3, Feno, or Metf increased PPAR $\alpha$ but decreased FAS expression levels in the liver (Figure 6). The adipose PPAR $\gamma$ and FAS expressions were increased in the HF group. Treatment with AnK1, AnK2, AnK3, Feno, or Metf decreased PPAR $\gamma$ and FAS expression levels in adipose tissue (Figure 7).

\section{Discussion}

Skeletal muscle and adipose tissue play unique roles in the regulation of insulin-dependent glucose homeostasis [39]. Skeletal muscle is proposed to be the primary site of wholebody insulin-mediated glucose uptake [15, 40, 41]. Adipose tissue accounts for a small fraction of glucose disposal after a meal, with the majority of glucose uptake by muscles [41, 42]. Therefore, this study was firstly designed to screen GLUT4 protein expression in in vitro myotubes. And we knew that if in vitro study of the compound displays effectiveness, it cannot be assumed to have the same effect in vivo, since it entered physical body and underwent biotransformation including absorption, distribution, metabolism, and excretion. Thus, this study was focused on performance of targeted gene protein expressions in different tissues of AnK-treated HFDfed mice. This study firstly observed that AnK treatment at 5, 10 , and $25 \mu \mathrm{g} / \mathrm{mL}$ in vitro significantly increased membrane expression levels of GLUT4 in C2C12 myoblast cells. We further undertake to assess whether AnK exhibit antidiabetic and antihyperlipidemic activity employing the HFD animal model since insulin resistance plays the majority of all diabetes cases and to compare with the antidiabetic drug, metformin, and the hypolipidemic drug, fenofibrate, which has also been shown to display good glycemic control [43]. Here we observed that HFD-induction was in line with the 


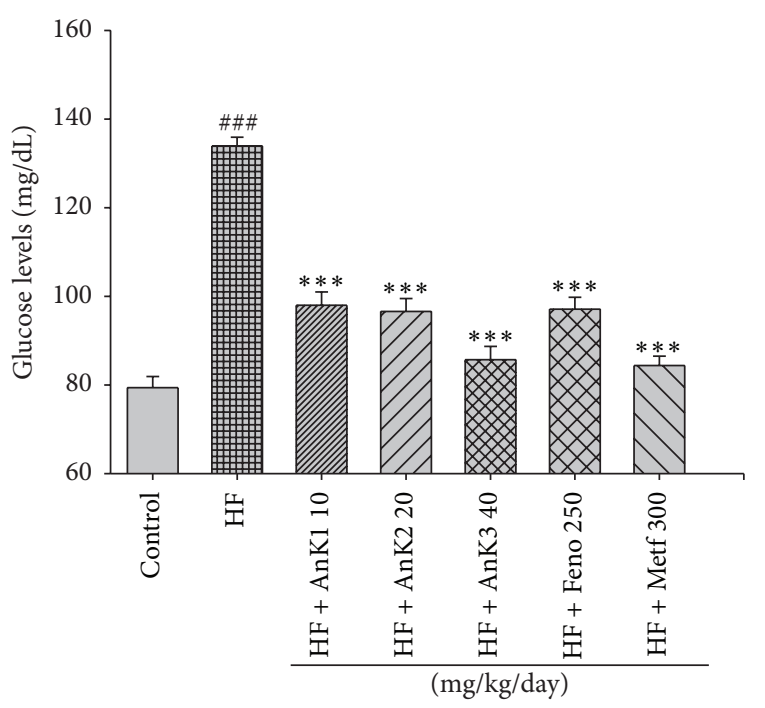

(a)

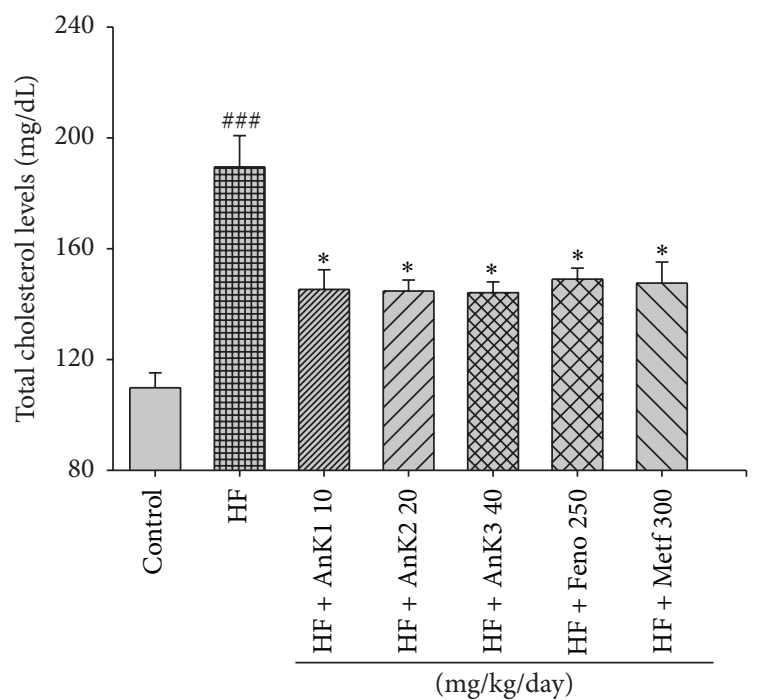

(c)

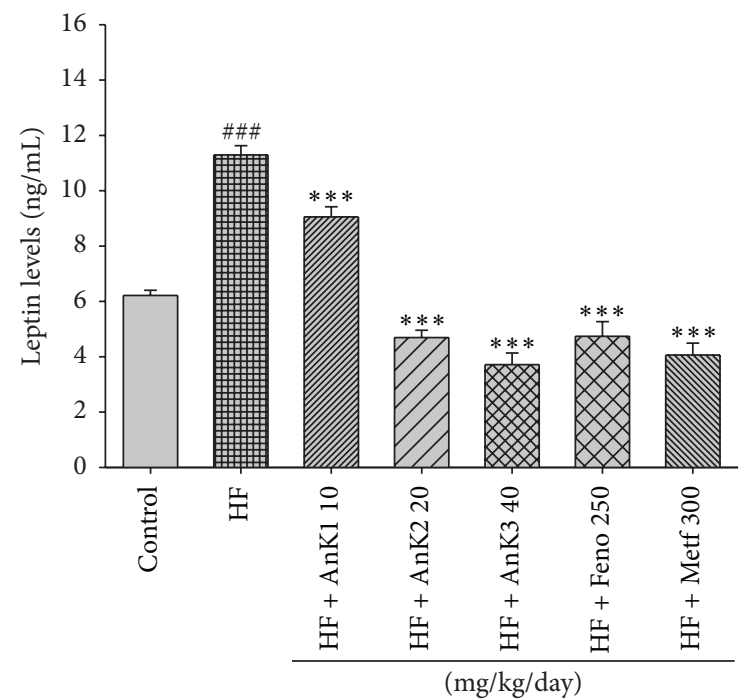

(e)

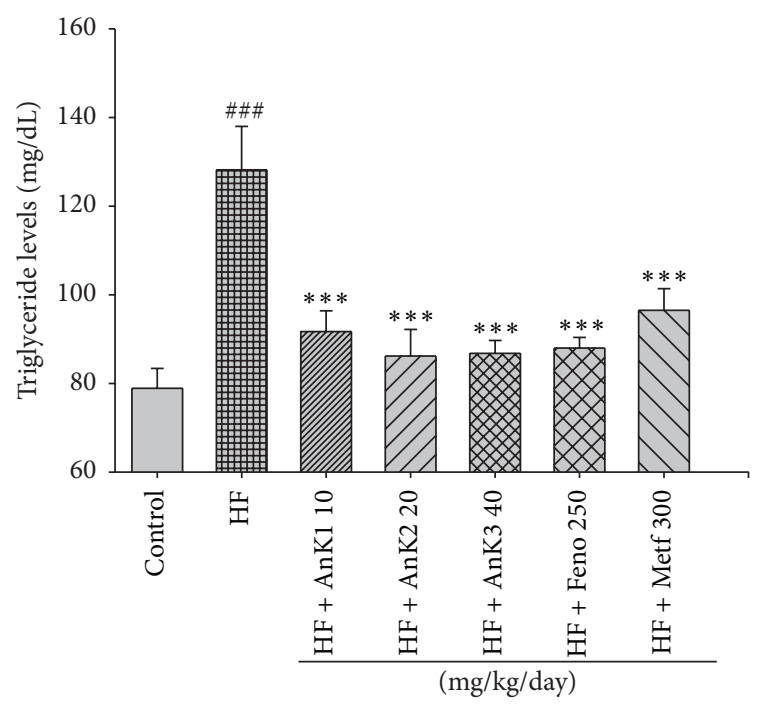

(b)

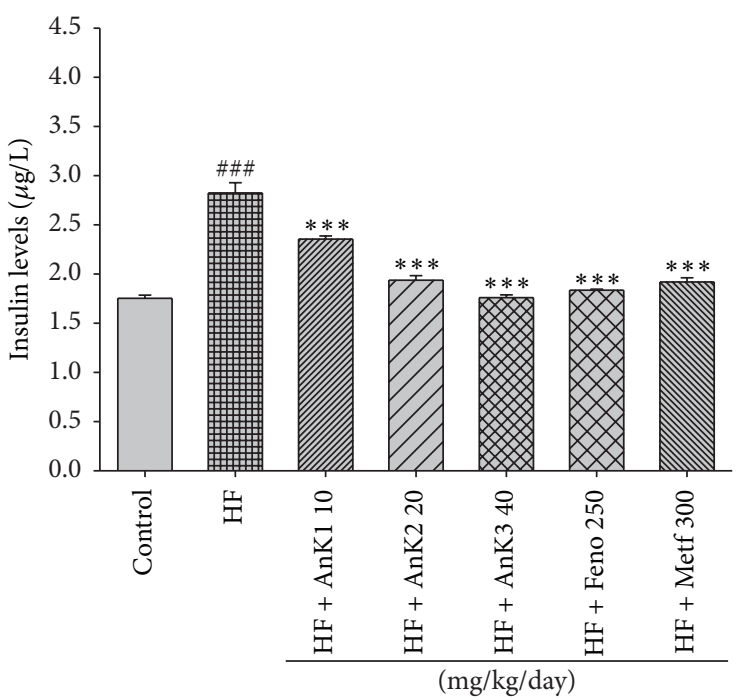

(d)

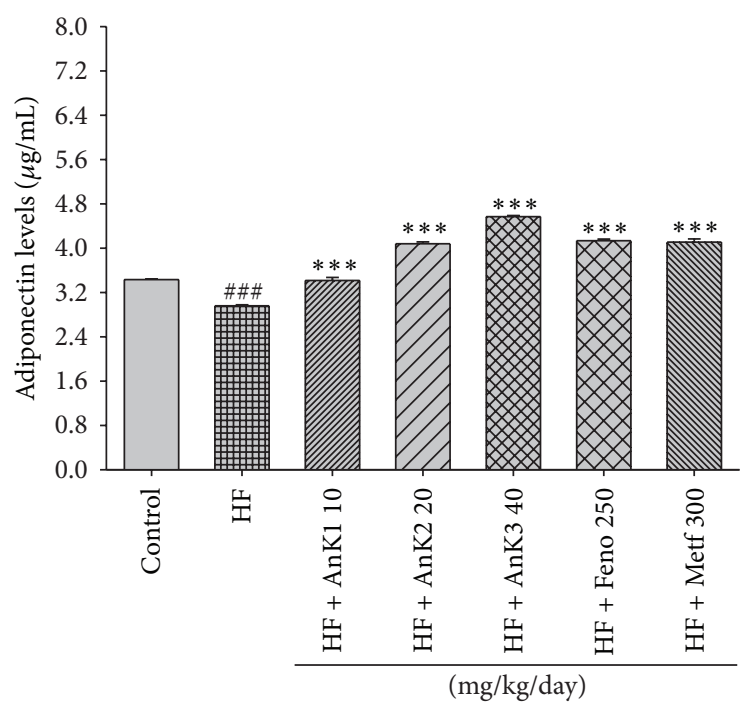

(f)

Figure 3: Continued. 


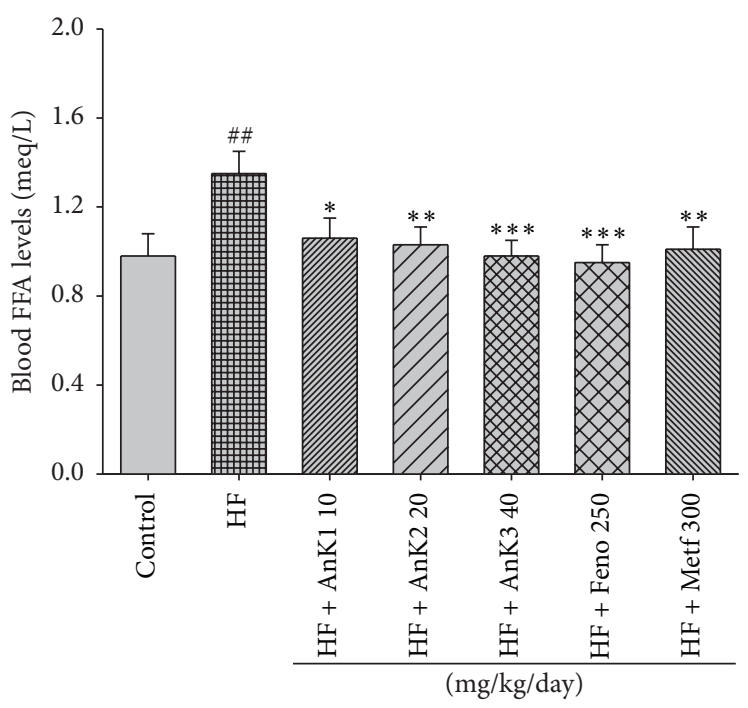

(g)

Figure 3: Effects of antcin K (AnK) on (a) blood glucose levels, (b) blood triglycerides levels, (c) blood total cholesterol levels, (d) insulin levels, (e) leptin levels, (f) adiponectin levels, and (g) blood FFA levels at week 12 . Mice were fed with $45 \%$ high-fat diet (HF) or low-fat diet (CON) for 12 weeks. After 8 weeks of induction, the HF mice were treated with vehicle, or antcin $\mathrm{K}$, or fenofibrate (Feno), or metformin (Metf) accompanied with HF diet for 4 weeks. All values are means \pm SE $(n=9)$. ${ }^{\# \#} P<0.01$ and ${ }^{\# \#} P<0.001$ compared with the control (CON) group; ${ }^{*} P<0.05,{ }^{* *} P<0.01$, and ${ }^{* * *} P<0.001$ compared with the high-fat diet plus vehicle (distilled water) (HF) group by ANOVA. AnK (AnK1, AnK2, or AnK3, 10, 20, or $40 \mathrm{mg} / \mathrm{kg}$ body wt); fenofibrate (Feno, $250 \mathrm{mg} / \mathrm{kg}$ body wt); metformin (Metf, $300 \mathrm{mg} / \mathrm{kg}$ body wt). FFA, plasm free fatty acid; visceral fat represented epididymal WAT plus retroperitoneal WAT.

previous observation displaying increases in blood glucose, triglyceride, total cholesterol, insulin, and leptin levels [26]. After the treatment, AnK exhibited both antidiabetic and antihyperlipidemic effects in HFD-fed mice. AnK-treated mice show the glucose-lowering effect by $26.8 \%-36.0 \%$. Of interest, the glucose-lowering effect of AnK at $40 \mathrm{mg} / \mathrm{kg}$ (with less than one-seventh of Meft dosage) was comparable to that of metformin. Our results demonstrated that AnK display good antidiabetic activities; moreover, AnK treatment decreased blood insulin levels and finally improved HFD- induced insulin resistance. These favorable antidiabetic effects of AnK were owing to enhancement of insulin sensitivity in peripheral tissues, particularly increased membrane GLUT4 expressions in skeletal muscle and enhanced activation of AMPK in muscle and the liver.

In addition, all of the AnK-treated groups decreased circulating triglyceride concentrations by $28.5 \%-32.8 \%$ comparable to that of Feno, which is a PPAR $\alpha$ agonist with triglyceride-lowering effect [43]. The overall effects in HFDfed mice imply that AnK had therapeutic potential for the management of type 2 diabetes accompanied with hyperlipidemia.

The first aim of this study was undertaken to assess muscular membrane GLUT4 expressions following treating HFD-fed mice with AnK. Skeletal muscle plays the major site of whole-body insulin-mediated glucose uptake [15]. The membrane GLUT4 expressions measured the translocation of insulin responsive glucose transporter GLUT4 to the plasma membrane [19]. In this study, treatment with AnK, Feno, or Metf significantly increased membrane expression levels GLUT4 by 1.52-2.20-, 1.98-, or 1.86- fold as compared with the HF group, respectively, implying that the increased membrane GLUT4 contents are enhanced to cause glucose uptake, resulting in a decrease in blood glucose levels.

Evidence suggests that the $\mathrm{C} 2 \mathrm{C} 12$ myotube is a useful model for analyzing GLUT4 translocation in skeletal muscle [44]. Akt (PKB) stimulates glucose uptake by modulating glucose transporter 4 (GLUT4) [45]. The promoted glucose uptake into skeletal muscle included two pathways: insulin-dependent mechanisms lead to activation of Akt and contraction-mediated stimulation of AMPK [12, 17]. In this in vitro experiment, our results showed that AnK (between 1 and $25 \mu \mathrm{g} / \mathrm{mL}$ ) was not toxic to $\mathrm{C} 2 \mathrm{C} 12$ myotubes by employing the MTT (3-[4,5-dimethylthiazol-2-yl]-2,5diphenyltetrazolium bromide) assay (data not shown), and AnK significantly enhanced membrane GLUT4 proteins and phospho-AMPK/total-AMPK expressions at 5, 10, and $25 \mu \mathrm{g} / \mathrm{mL}$ and enhanced phospho-Akt/total-Akt expressions at 10 and $25 \mu \mathrm{g} / \mathrm{mL}$, and we assume that AnK in myotube cells at 10 and $25 \mu \mathrm{g} / \mathrm{mL}$ could stimulate glucose transport activity partly by insulin pathway and partly by AMPK activation.

The second aim of this study was to evaluate the phospho-AMPK protein expression in AnK-treated HFDfed mice, since AMPK plays the core role of glucose and lipid metabolism. These data showed that AnK treatment increased the expressions of phospho-AMPK/total-AMPK in the muscle and liver. Metformin may enhance skeletal muscular AMPK activity [17, 46]. Chronic activation of AMPK may induce GLUT4 deployment to the plasma 
$\mathrm{CON}$

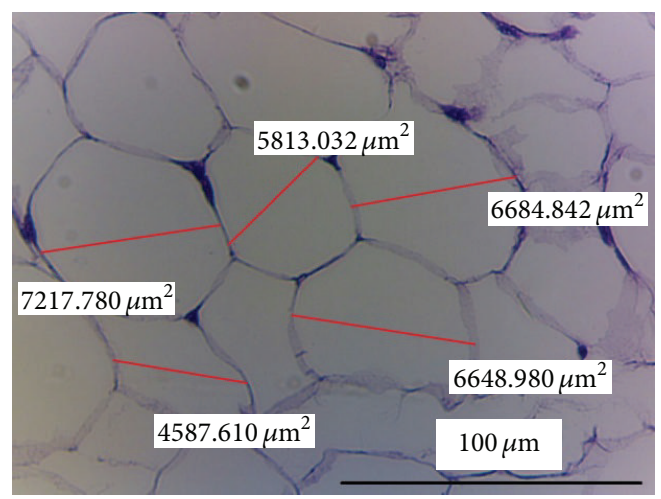

$\mathrm{HF}+\mathrm{AnK} 1$

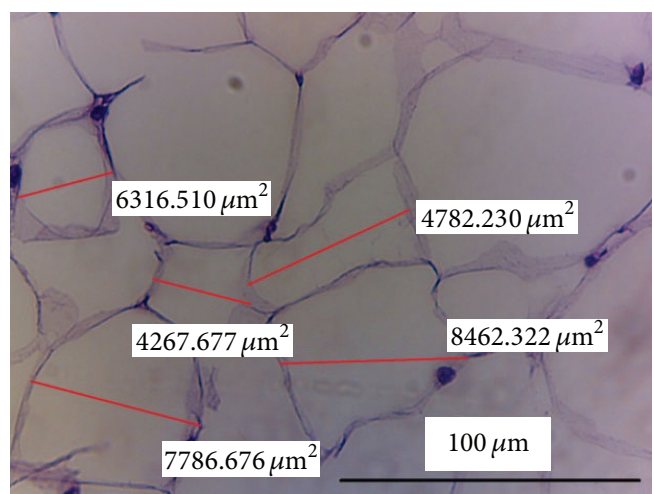

$\mathrm{HF}+\mathrm{AnK} 3$

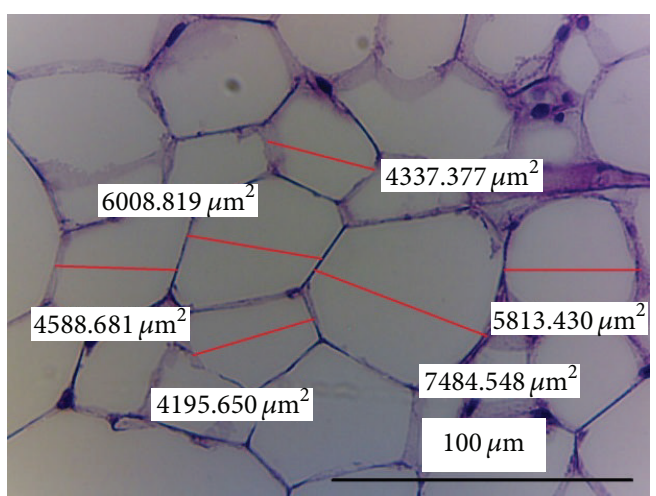

HF

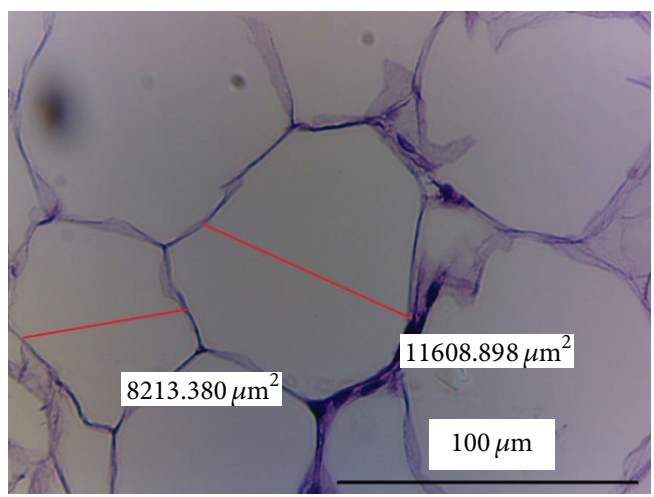

$\mathrm{HF}+\mathrm{AnK} 2$

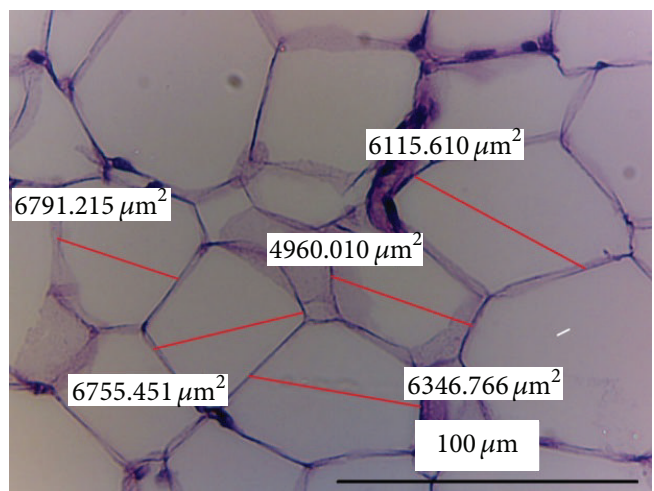

$\mathrm{HF}+\mathrm{Feno}$

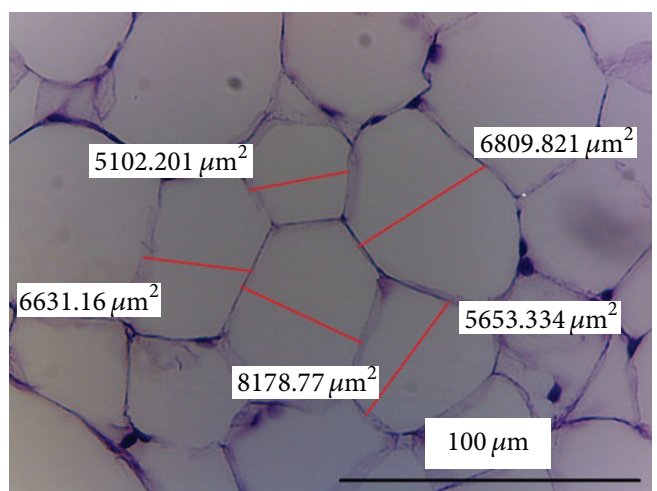

HF + Metf

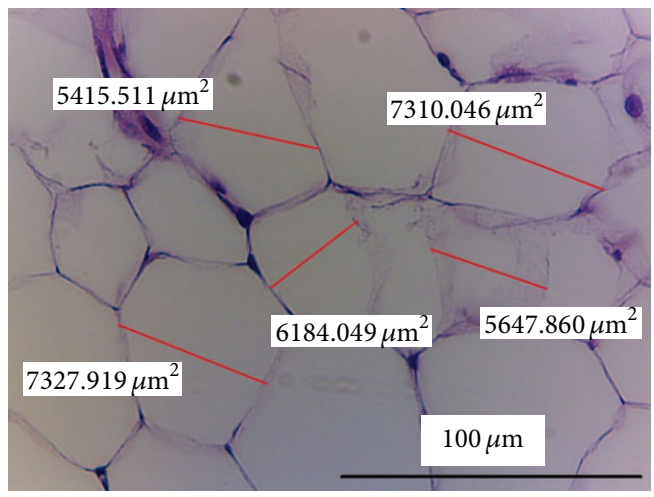

(a)

Figure 4: Continued. 
$\mathrm{CON}$

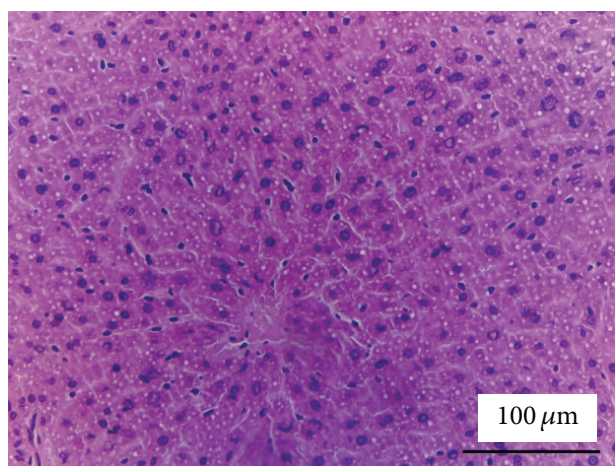

$\mathrm{HF}+\mathrm{AnK} 1$

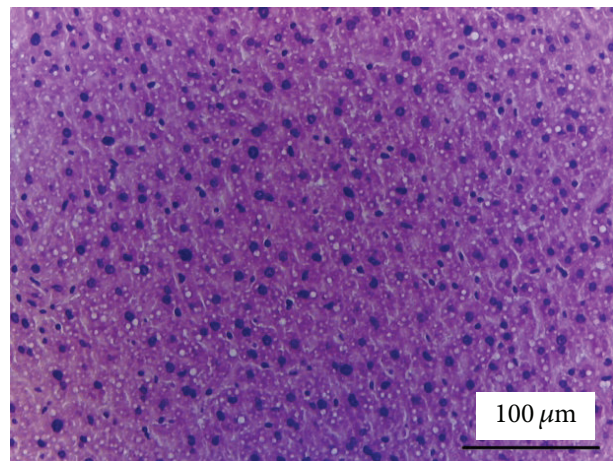

$\mathrm{HF}+\mathrm{AnK} 3$

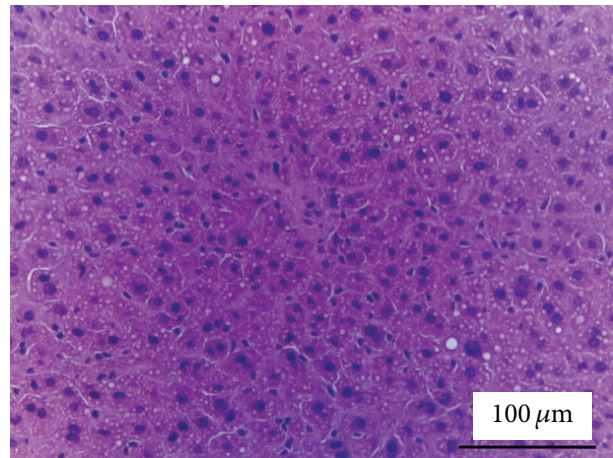

HF

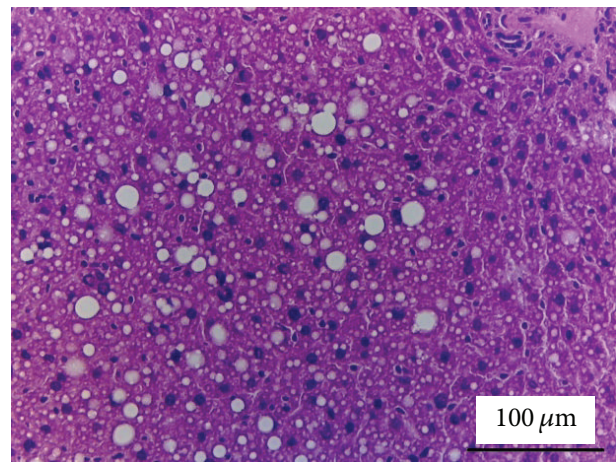

$\mathrm{HF}+\mathrm{AnK} 2$

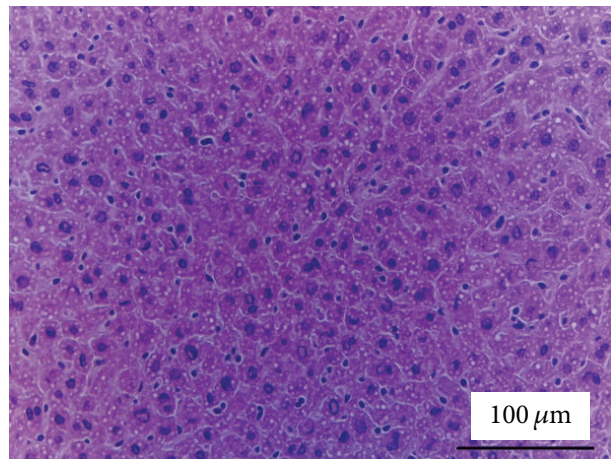

$\mathrm{HF}+\mathrm{Feno}$

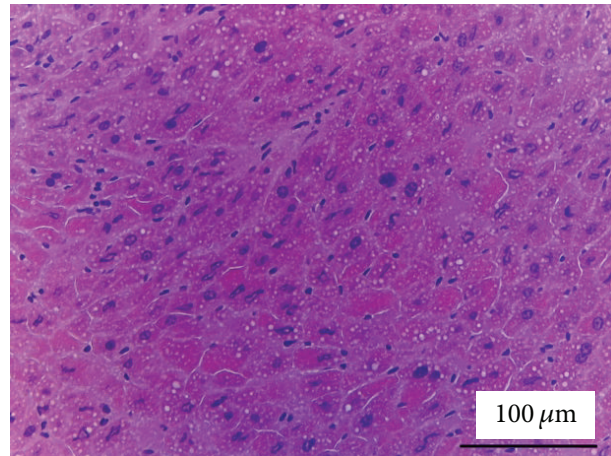

$\mathrm{HF}+$ Metf

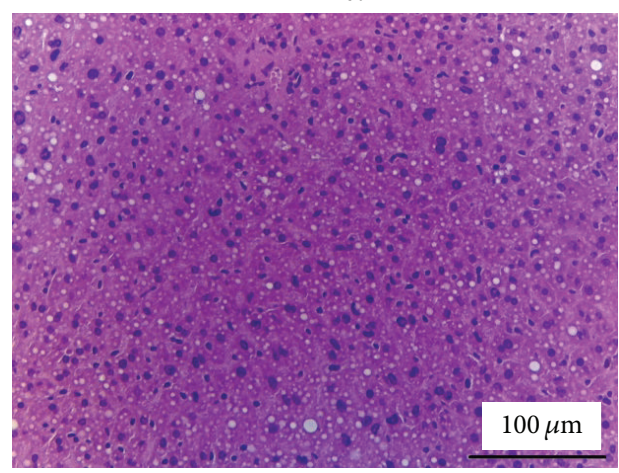

(b)

FIgURE 4: Histology of (a) epididymal white adipose tissue and (b) liver tissue of mice in the control (CON), high-fat diet plus vehicle (distilled water) (HF), HF + AnK1, HF + AnK2, HF + AnK3, HF + fenofibrate (Feno), or HF + metformin (Metf) groups by hematoxylin and eosin-staining. Magnification: 10 (ocular) × 20 (object lens). Antcin K (AnK1, AnK2, or AnK3, 10, 20, or 40 mg/kg body weight, resp.); Feno, fenofibrate $(250 \mathrm{mg} / \mathrm{kg}$ body weight). Metf, metformin $(300 \mathrm{mg} / \mathrm{kg}$ body weight). 


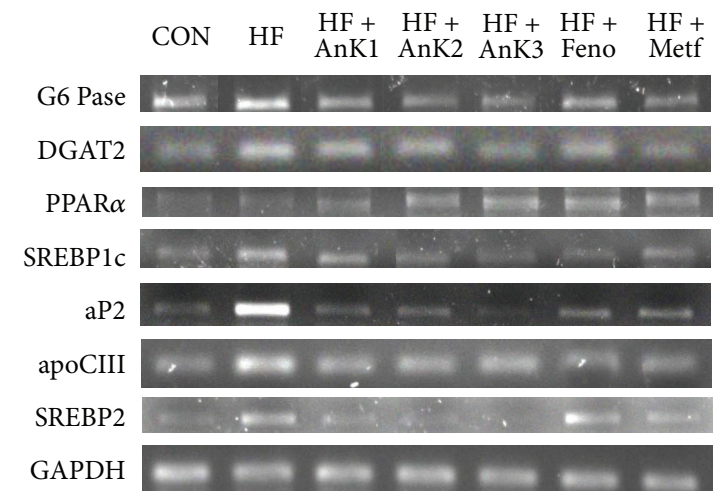

(a)

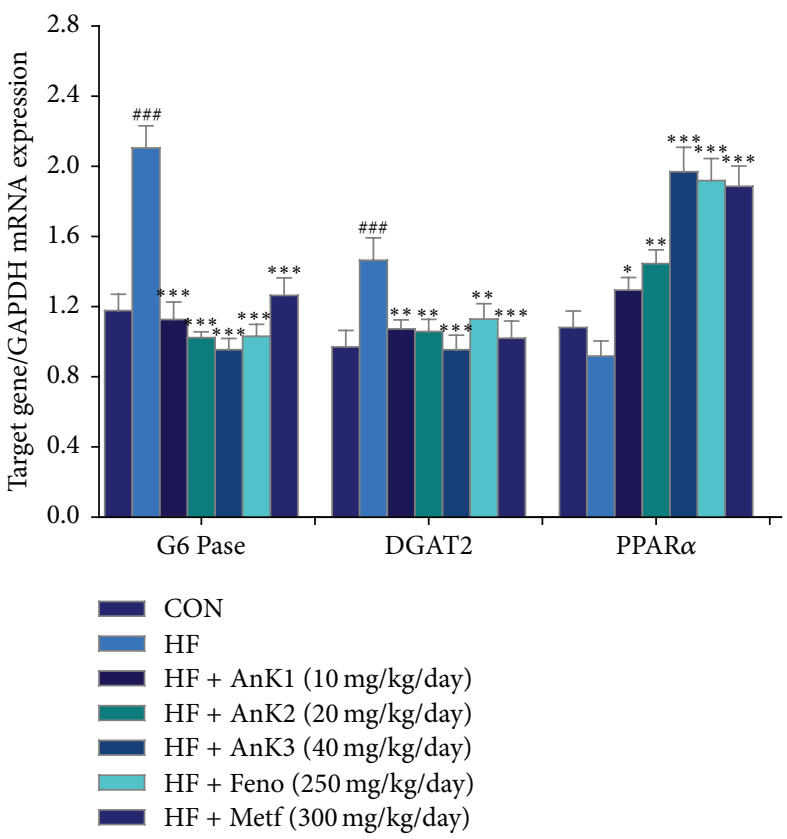

(b)

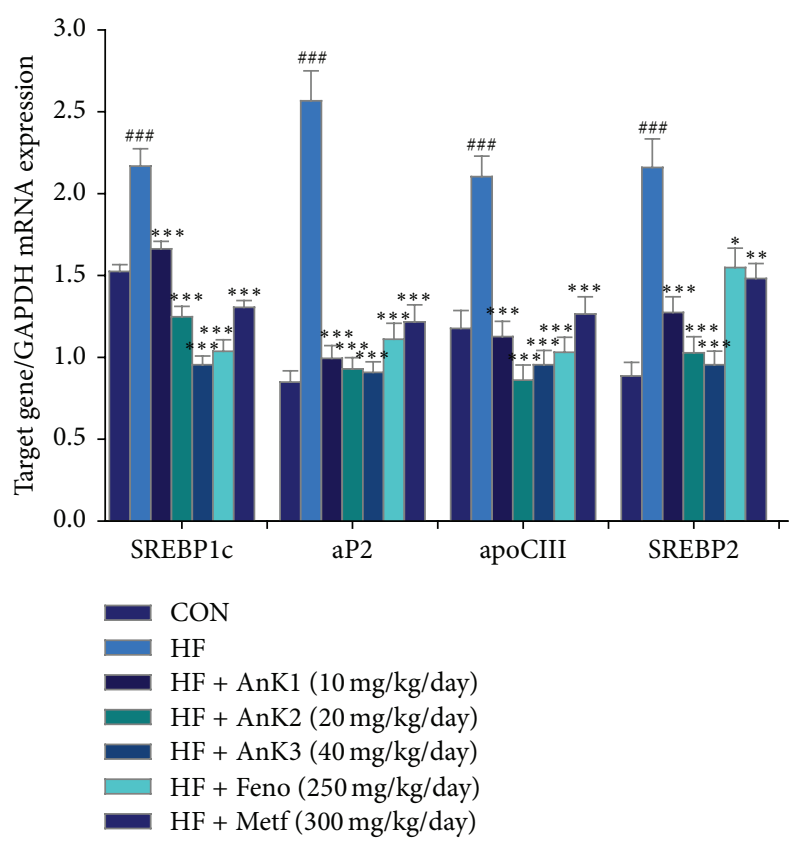

(c)

FIgURE 5: Semiquantitative RT-PCR analysis on G6 Pase, DGAT2, PPAR $\alpha$, SREBP1c, aP2, apoCIII, and SREBP2 mRNA levels in liver tissue of the mice by oral gavage antcin K (AnK1, AnK2, or AnK3, 10, 20, or $40 \mathrm{mg} / \mathrm{kg}$ body weight, resp.); Feno, fenofibrate (250 mg/kg body weight); Metf, metformin (300 mg/kg body weight): (a) representative image; (b, c) quantification of the ratio of target gene to GAPDH mRNA expression. Total RNA $(1 \mu \mathrm{g})$ isolated from tissue was reverse-transcribed by MMLV-RT; $10 \mu \mathrm{L}$ of RT products was used as templates for PCR. The expression levels of G6 Pase, DGAT2, PPAR $\alpha$, SREBP1c, aP2, apoCIII, and SREBP2 mRNA were measured and quantified by image analysis. Values were normalized to GAPDH mRNA expression. All values are means \pm SE $(n=9)$. ${ }^{\# \# ~} P<0.001$ compared with the control (CON) group; ${ }^{*} P<0.05,{ }^{* *} P<0.01$, and ${ }^{* * *} P<0.001$ compared with the high-fat-diet plus vehicle (distilled water) (HF) group.

membrane, leading to insulin-independent glucose uptake $[17,46,47]$. In skeletal muscle, AnK was found to increase AMPK phosphorylation comparable to that of metformin, suggesting that AnK activates AMPK or Akt phosphorylation to increase GLUT4 translocation in muscles, which leads to a decrease in systemic insulin resistance.

G6 Pase plays a key role in gluconeogenesis [48]. The hepatic expression of mRNA level of G6 Pase is reduced in AnK-treated mice. Collectively, our results imply that AnK display glucose-lowering effects via enhanced muscular GLUT4 proteins to increase glucose uptake and decreased hepatic G6 Pase mRNA levels to suppress hepatic glucose production.
The third aim of this study was to clarify the hypolipidemic effects and mechanisms of AnK. Evidences have shown that PPAR $\alpha$ are abundantly expressed in the liver tissue and promoted fatty acids oxidation [49]. PPAR $\alpha$ agonists have been proposed as a breakthrough in the management of dyslipidemia to reduce blood triglyceride levels [43, 49]. In this study, AnK displayed antihypertriglyceridemic effects. PPAR $\alpha$ ligands could reduce the expression of the apo CIII gene [50], thus resulting in hypotriglyceridemic effect. DGAT2 play a role in the final step of triglyceride synthesis [51]. SREBP-1c, a key lipogenic transcription factor, stimulates lipogenic enzyme expression and contributes to fatty acids synthesis and TG accumulation [52]. Mice with 


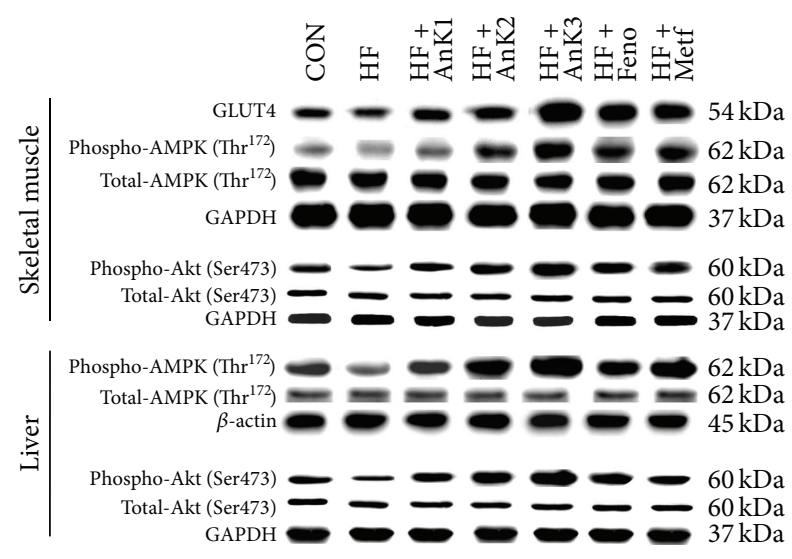

(a)

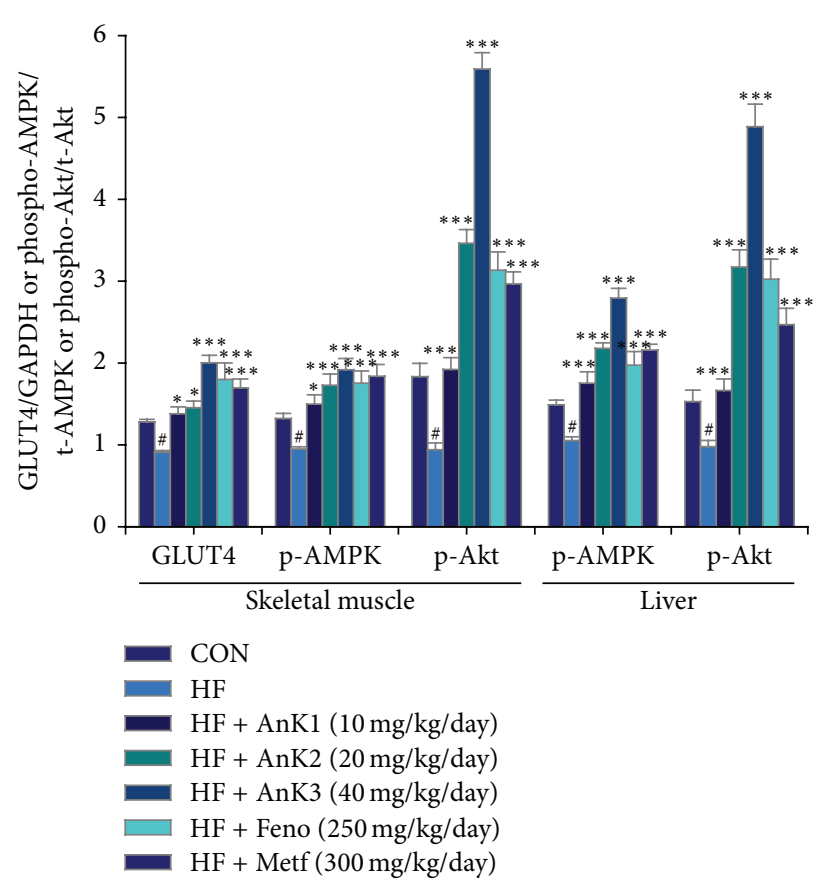

(b)

FIGURE 6: GLUT4 protein contents in skeletal muscle or phosphoAkt/t-Akt or phospho-AMPK $\left(\mathrm{Thr}^{172}\right) / \mathrm{t}$-AMPK in liver and skeletal muscle of the mice by oral gavage antcin $\mathrm{K}$ (AnK): (a) representative image; (b) quantification of the GLUT4 expression levels, the ratio of phospho-AMPK to total-AMPK, or phospho-Akt/t-Akt expression levels (mean \pm SE, $n=9$ ). Protein was separated by $12 \%$ SDS PAGE detected by Western blot. ${ }^{\#} P<0.05$ compared with the control (CON) group; ${ }^{*} P<0.05$ and ${ }^{* * *} P<0.001$ compared with the highfat-diet plus vehicle (distilled water) (HF) group. Antcin K (AnK1, AnK2, or AnK3, 10, 20, or $40 \mathrm{mg} / \mathrm{kg}$ body weight, resp.); Feno, fenofibrate $(250 \mathrm{mg} / \mathrm{kg}$ body weight); Metf, metformin $(300 \mathrm{mg} / \mathrm{kg}$ body weight).

aP2 deficiency are protected from the development of dyslipidemia, hyperglycemia, insulin resistance, and fatty liver disease in both genetic and dietary obesity [53]. Ablation of aP2 and mall show enhanced liver accumulation of longer-chain fatty acids, thus resulting in decreased SREBP1c expressions and its several downstream lipogenic enzymes [53]. We found that hepatic mRNA levels of aP2 and lipogenic SREBP1c are suppressed by AnK, thus also contributing to protecting from HFD-induced insulin resistance and hepatic steatosis. FAS is a critical focus in fatty acid synthesis [54]. SREBP2 play a core role in the regulation of cholesterol synthesis [55]. AnK lowered plasma TC concentrations coincident with reduced SREBP2 mRNA levels, implying AnK exerting TC-lowering effect may be primarily due to a decrease of cholesterol synthesis. Taken together, AnK-treated mice had increased hepatic expression of PPAR $\alpha$ protein to enhance fatty acids oxidation but decreased FAS protein to inhibit fatty acids synthesis coincident with suppressed SREBP1c, aP2, DGAT2, and apo CIII mRNAs, thus contributing to the hepatic triglyceride output and leading to decreased plasma triglycerides, hepatic steatosis, and total cholesterol levels.

In adipose tissue, PPAR $\gamma$ stimulated adipogenesis and lipogenesis [56]. PPAR $\gamma$ is abundantly expressed in adipocytes and its expression is markedly induced during adipocyte differentiation [57]. Here we report that treatment with AnK, Feno, or Metf decreased adipose expression of PPAR $\gamma$ and FAS protein; as a result, adipogenesis and fatty acids synthesis and lipid accumulation are reduced in adipose tissue. Moreover, blood TG is fluctuating between the liver and adipose tissue. Lipid could usually be stored in the adipose tissue and the liver is the major organ of lipid metabolism, presuming AnK could remove fat from adipose tissue to peripheral tissues not only by increasing lipid catabolism including inhibition of fatty acid synthesis (FAS) and enhancement of fatty acid oxidation (PPAR $\alpha)$ in the liver, but also by inhibition of adipocyte adipogenesis $(\operatorname{PPAR} \gamma)$ and FAS in adipose tissue, thus leading to reduced TG levels in the liver, blood, and adipose tissue. Therefore, in histology analysis, AnK treatment resulted in a decrease in lipid accumulation in adipose tissue and liver and finally reflected hepatic lipid drops almost invisible and a reduction in adipocyte size.

Adiponectin level was found to decrease in HFD-fed mice in this study. This observation is in line with the others demonstrating that adiponectin levels are reduced in adults or rodents with obesity and type 2 diabetes [58]. High levels of adiponectin can predict enhanced insulin sensitivity of both glucose and lipid metabolism [59]. Following AnK administration, the mice display significantly increased blood levels of adiponectin, establishing that AnK could provide a unique therapeutic advantage associated with the regulation to improve insulin sensitivity. Moreover, studies have showed that there is an inverse relationship between plasma leptin or mRNA expression of leptin and insulin sensitivity [60]. In this study, leptin level is enhanced in HFD-fed mice, in accordance with a previous report [61]. Treatment with AnK markedly reduced the increase of leptin level. Thus, AnK prevented HFD-induced abnormalities in leptin levels and improved insulin resistance. Treatment with globular domain of adiponectin increased glucose uptake and AMPK activation [62]. Adiponectin is proposed to activate AMPK in the liver, enhance glucose utilization and fatty acid oxidation, and inhibit glucose production in the liver [63]. Administration of AnK significantly elevated phosphorylation of AMPK. On the basis of the previous reports $[62,64]$, the 


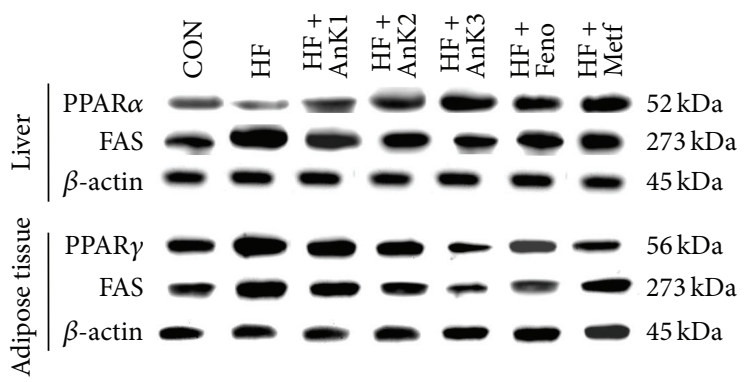

(a)

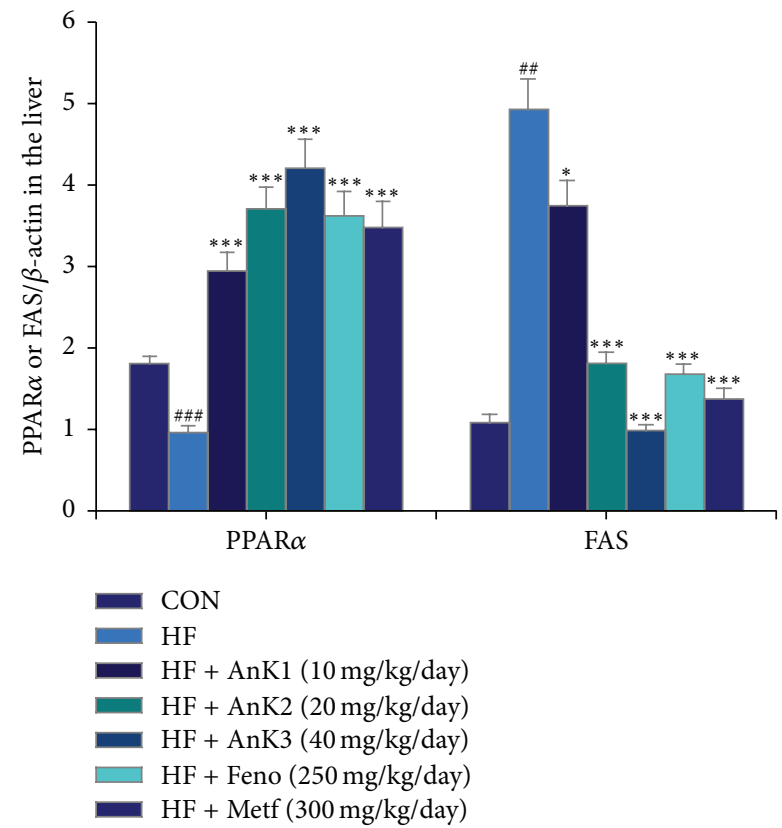

(b)

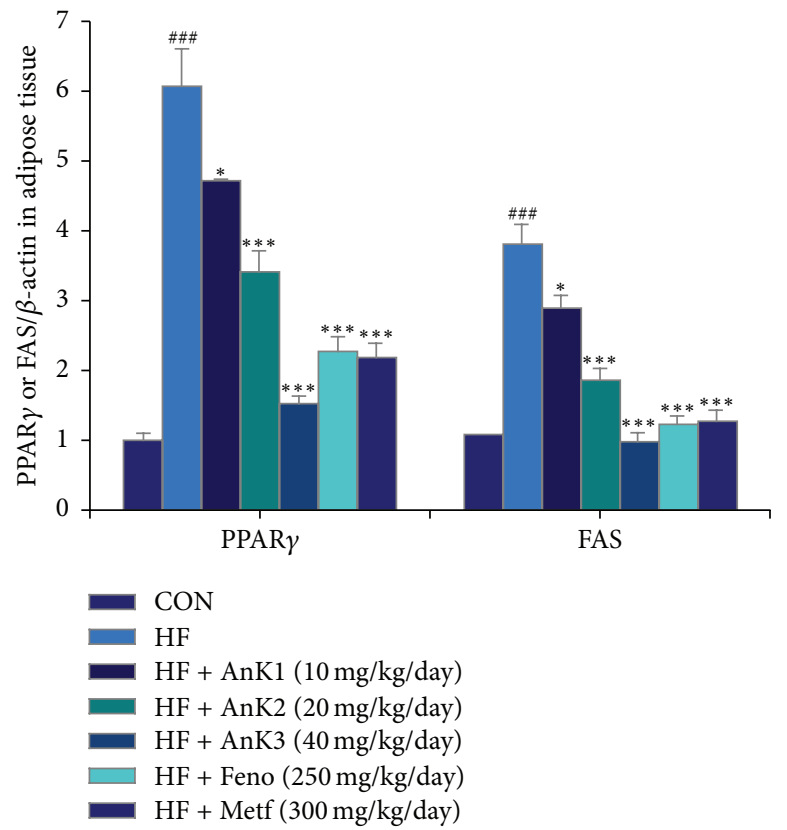

(c)

FIgURE 7: Expression levels of PPAR $\alpha$ and FAS in the liver tissue and PPAR $\gamma$ and FAS in adipose tissue of mice by oral gavage antcin K: (a) representative image; (b, c) quantification of the expression levels of PPAR $\alpha$ and FAS in the liver tissue and PPAR $\gamma$ and FAS in adipose tissue. Protein was separated by $12 \%$ SDS PAGE detected by Western blot. ${ }^{\# \#} P<0.01$ and ${ }^{\# \#} P<0.001$ compared with the control (CON) group; ${ }^{*} P<0.05$ and ${ }^{* * *} P<0.001$ compared with the high-fat-diet plus vehicle (distilled water) (HF) group. Antcin K (AnK1, AnK2, or AnK3, 10, 20 , or $40 \mathrm{mg} / \mathrm{kg}$ body weight, resp.); Feno, fenofibrate ( $250 \mathrm{mg} / \mathrm{kg}$ body weight); Metf, metformin (300 mg/kg body weight).

AMPK phosphorylation by AnK may be associated with adiponectin and/or leptin secretion. Thus, there is possibility that AnK directly cause AMPK phosphorylation or act by adiponectin-mediated activation of AMPK and PPAR $\alpha$ leads to a reduction in hepatic gluconeogenesis and increased muscle glucose uptake, resulting in reduced glucose levels in vivo and increased fatty acid oxidation in both tissues.

In conclusion, AnK-treated mice had not only lowered blood glucose and insulin, but also decreased triglyceride, total cholesterol levels, and finally ameliorated insulin resistance (Figure 8). Of interest, AnK at $40 \mathrm{mg} / \mathrm{kg} /$ day dosage displayed both antihyperglycemic effect comparable to Metf $(300 \mathrm{mg} / \mathrm{kg} /$ day $)$ and antihypertriglyceridemic effect comparable to Feno $(250 \mathrm{mg} / \mathrm{kg} /$ day $)$. The antidiabetic effect of AnK is due to significant increases in membrane GLUT4 expression levels in skeletal muscle to stimulate glucose uptake coincident with decreases in G6 Pase mRNA levels to inhibit hepatic glucose production, thus contributing to glucose-lowering efficacy. In both skeletal muscle and liver tissue, AnK-treated mice had increased AMPK activation. AnK treatment exhibited inhibition of hepatic lipogenic FAS expression but enhancement of fatty acid oxidation PPAR $\alpha$ expression coincident with reduced SREBP1c mRNA levels in the liver, thus resulting in decreased plasma triglycerides and total cholesterol levels. AnK activates AMPK or Akt phosphorylation to increase GLUT4 translocation in muscles, which leads to a decrease in systemic insulin resistance and to fat accumulation in adipose tissue and liver. Additionally, the ameliorated insulin resistance also improved the liver insulin sensitivity (Akt activation). Our findings manifest that AnK has a favorable therapeutic potential for the management of type 2 diabetes associated with hyperlipidemia. 


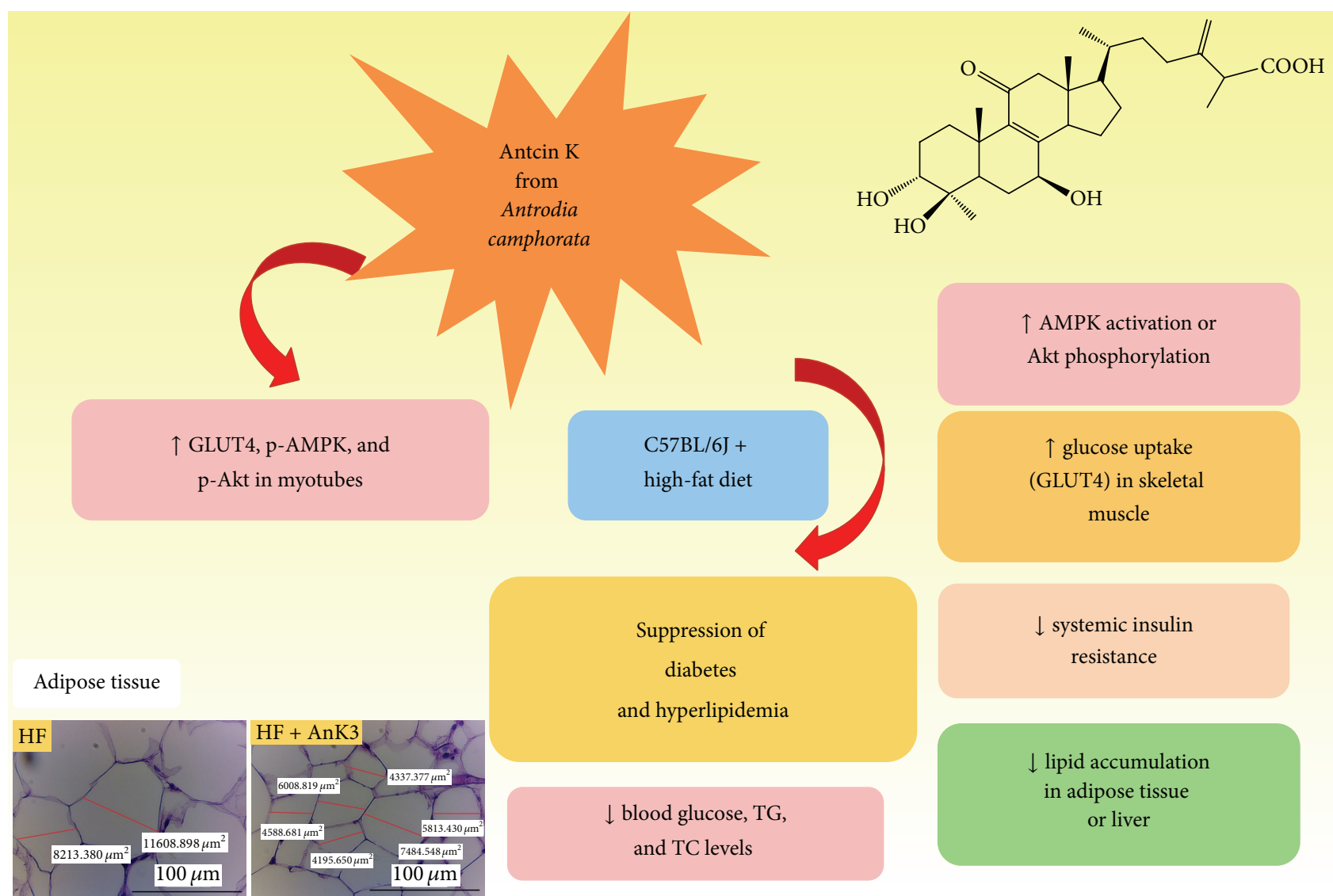

FIGURE 8: A proposed mechanism for AnK to improve diabetes and hyperlipidemia.

\section{Abbreviations}

AMPK: AMP-activated protein kinase

aP2: $\quad$ Adipocyte fatty acid binding protein 2

BAT: Brown adipose tissue

CON: Control

DGAT2: Acyl-coenzyme A: diacylglycerol acyltransferase 2

EWAT: Epididymal white adipose tissue

FAS: $\quad$ Fatty acid synthase

Feno: Fenofibrate

FFA: Free fatty acid

GAPDH: Glyceraldehyde-3-phosphate dehydrogenase

G6 Pase: Glucose-6-phosphatase

GLUT4: Glucose transporter 4

HF: High-fat control

HFD: High-fat diet

Metf: Metformin

MWAT: Mesenteric white adipose tissue

PPAR: Peroxisome proliferator-activated receptor
RT-PCR: Reverse transcription-polymerase chain reaction

RWAT: Retroperitoneal white adipose tissue

SREBP: Sterol regulatory element binding protein

TC: Total cholesterol

TG: $\quad$ Triglyceride

WAT: White adipose tissue.

\section{Competing Interests}

The authors wish to confirm that there are no known competing interests associated with this paper and there has been no significant financial support for this work that could have influenced its outcome.

\section{Authors' Contributions}

Yueh-Hsiung Kuo and Cheng-Hsiu Lin equally contributed to this paper.

\section{Acknowledgments}

Financial support was partly provided by the Chinese Medical University under the aim for Top University Plan of the Ministry of Education, Taiwan, and Taiwan Ministry of 
Health and Welfare Clinical Trial and Research Center of Excellence (MOHW105-TDU-B-212-133019).

\section{References}

[1] A. Green, N. C. Hirsch, and S. K. Pramming, "The changing world demography of type 2 diabetes," Diabetes/Metabolism Research and Reviews, vol. 19, no. 1, pp. 3-7, 2003.

[2] S. O'Rahilly, R. C. Turner, and D. R. Matthews, "Impaired pulsatile secretion of insulin in relatives of patients with noninsulin-dependent diabetes," New England Journal of Medicine, vol. 318, no. 19, pp. 1225-1230, 1988.

[3] M. Geethangili and Y.-M. Tzeng, "Review of pharmacological effects of Antrodia camphorata and its bioactive compounds," Evidence-Based Complementary and Alternative Medicine, vol. 2011, Article ID 212641, 17 pages, 2011.

[4] G.-J. Huang, J.-S. Deng, S.-S. Huang et al., "Hepatoprotective effects of eburicoic acid and dehydroeburicoic acid from Antrodia camphorata in a mouse model of acute hepatic injury," Food Chemistry, vol. 141, no. 3, pp. 3020-3027, 2013.

[5] T.-Y. Song and G.-C. Yen, "Protective effects of fermented filtrate from Antrodia camphorata in submerged culture against CCl4-induced hepatic toxicity in rats," Journal of Agricultural and Food Chemistry, vol. 51, no. 6, pp. 1571-1577, 2003.

[6] M. Ye and Y. M. Tzeng, "Chemistry and DMPK studies of Antrodiam camphorata," in Fruiting Body's Standards and the Correct Scientific Name of Niu-Chang Musroom Antrodia cinnamomea [on Cinnamomum kanehirai] Endemic in Taiwan \& the Original Record of 2014 International Symposium and Workshop on Taiwan Medical Mushrooms: Antrodia cinnamomea, Academic Sinica, Taipei, Taiwan, 2014.

[7] C. I. Lai, Y. L. Chu, C. T. Ho, Y. C. Su, Y. H. Kuo, and L. Y. Sheen, "Antcin $\mathrm{K}$, an active triterpenoid from the fruiting bodies of basswood cultivated A. cinnamomea, induces mitochondria and endoplasmic reticulum stress-mediated apoptosis in human hepatoma cells," Journal of Traditional and Complementary Medicine, vol. 6, no. 1, pp. 48-56, 2016.

[8] Y.-C. Shen, Y.-H. Wang, Y.-C. Chou et al., "Evaluation of the anti-inflammatory activity of zhankuic acids isolated from the fruiting bodies of Antrodia camphorata," Planta Medica, vol. 70, no. 4, pp. 310-314, 2004.

[9] Y.-M. Tzeng and M. Geethangili, "Review of pharmacological effects of Antrodia camphorata and its bioactive compounds," Evidence-Based Complementary and Alternative Medicine, vol. 2011, Article ID 212641, 17 pages, 2011.

[10] Y.-H. Kuo, C.-H. Lin, and C.-C. Shih, "Ergostatrien-3 $\beta$-ol from Antrodia camphorata inhibits diabetes and hyperlipidemia in high-fat-diet treated mice via regulation of hepatic related genes, glucose transporter 4, and AMP-activated protein kinase phosphorylation," Journal of Agricultural and Food Chemistry, vol. 63, no. 9, pp. 2479-2489, 2015.

[11] Y. H. Kuo, C.-H. Lin, and C.-C. Shih, "Antidiabetic and antihyperlipidemic properties of a triterpenoid compound, dehydroeburicoic acid, from Antrodia camphorata in vitro and in streptozotocin-induced mice," Journal of Agricultural and Food Chemistry, vol. 63, no. 46, pp. 10140-10151, 2015.

[12] S. Huang and M. P. Czech, “The GLUT4 glucose transporter," Cell Metabolism, vol. 5, no. 4, pp. 237-252, 2007.

[13] N. J. Bryant, R. Govers, and D. E. James, "Regulated transport of the glucose transporter GLUT4," Nature Reviews Molecular Cell Biology, vol. 3, no. 4, pp. 267-277, 2002.
[14] B. Holmes and G. L. Dohm, "Regulation of GLUT4 gene expression during exercise," Medicine and Science in Sports and Exercise, vol. 36, no. 7, pp. 1202-1206, 2004.

[15] J. W. Ryder, J. Yang, D. Galuska et al., "Use of a novel impermeable biotinylated photolabeling reagent to assess insulinand hypoxia-stimulated cell surface GLUT4 content in skeletal muscle from type 2 diabetic patients," Diabetes, vol. 49 , no. 4 , pp. 647-654, 2000.

[16] A. Sriwijitkamol, D. K. Coletta, E. Wajcberg et al., "Effect of acute exercise on AMPK signaling in skeletal muscle of subjects with type 2 diabetes: a time-course and dose-response study," Diabetes, vol. 56, no. 3, pp. 836-848, 2007.

[17] R. W. A. Mackenzie and B. T. Elliott, "Akt/PKB activation and insulin signaling: a novel insulin signaling pathway in the treatment of type 2 diabetes," Diabetes, Metabolic Syndrome and Obesity: Targets and Therapy, vol. 7, pp. 55-64, 2014.

[18] M. Jing, V. K. Cheruvu, and F. Ismail-Beigi, "Stimulation of glucose transport in response to activation of distinct AMPK signaling pathways," American Journal of Physiology -Cell Physiology, vol. 295, no. 5, pp. C1071-C1082, 2008.

[19] G. Zhou, R. Myers, Y. Li et al., "Role of AMP-activated protein kinase in mechanism of metformin action," Journal of Clinical Investigation, vol. 108, no. 8, pp. 1167-1174, 2001.

[20] B. Viollet, B. Guigas, N. Sanz Garcia, J. Leclerc, M. Foretz, and F. Andreelli, "Cellular and molecular mechanisms of metformin: an overview," Clinical Science, vol. 122, no. 6, pp. 253-270, 2012.

[21] S.-C. Hsu and C.-J. Huang, "Reduced fat mass in rats fed a high oleic acid-rich safflower oil diet is associated with changes in expression of hepatic PPAR $\alpha$ and adipose SREBP-1c-regulated genes," Journal of Nutrition, vol. 136, no. 7, pp. 1779-1785, 2006.

[22] R. A. K. Srivastava, R. Jahagirdar, S. Azhar, S. Sharma, and C. L. Bisgaier, "Peroxisome proliferator-activated receptor- $\alpha$ selective ligand reduces adiposity, improves insulin sensitivity and inhibits atherosclerosis in LDL receptor-deficient mice," Molecular and Cellular Biochemistry, vol. 285, no. 1-2, pp. 3550, 2006.

[23] S. Kersten, B. Desvergne, and W. Wahli, "Roles of PPARS in health and disease," Nature, vol. 405, no. 6785, pp. 421-424, 2000 .

[24] M. Farnier, F. Bonnefous, N. Debbas, and A. Irvine, "Comparative efficacy and safety of micronised fenofibrate and simvastatin in patients with primary type IIa or IIb hyperlipidemia," Archives of Internal Medicine, vol. 154, no. 4, pp. 441-449, 1994.

[25] M. S. Winzell and B. Ahrén, "The high-fat diet-fed mouse: a model for studying mechanisms and treatment of impaired glucose tolerance and type 2 diabetes," Diabetes, vol. 53, no. 3 , pp. S215-S219, 2004.

[26] R. A. Harte, E. A. Kirk, M. E. Rosenfeld, and R. G. LeBoeuf, "Initiation of hyperinsulinemia and hyperleptinemia is diet dependent in C57BL/6 mice," Hormone and Metabolic Research, vol. 31, no. 10, pp. 570-575, 1999.

[27] A. E. Petro, J. Cotter, D. A. Cooper, J. C. Peters, S. J. Surwit, and R. S. Surwit, "Fat, carbohydrate and calories in the development of diabetes and obesity in the C57BL/6J mouse," Metabolism, vol. 53, no. 4, pp. 454-457, 2004.

[28] S. C. Stein, A. Woods, N. A. Jones, M. D. Davison, and D. Cabling, "The regulation of AMP-activated protein kinase by phosphorylation," Biochemical Journal, vol. 345, no. 3, pp. 437$443,2000$.

[29] C. C. Shen, Y. C. Kuo, R. L. Huang, L. C. Lin, M. J. Don, and T. T. Chang, "New ergostane and lanostane from Antrodia 
camphorata," The Journal of Chinese Medicine, vol. 14, no. 4, pp. 247-258, 2003.

[30] A. Klip, T. Ramlal, D. A. Young, and J. O. Holloszy, "Insulininduced translocation of glucose transporters in rat hindlimb muscles," FEBS Letters, vol. 224, no. 1, pp. 224-230, 1987.

[31] C.-C. Shih, C.-H. Lin, W.-L. Lin, and J.-B. Wu, "Momordica charantia extract on insulin resistance and the skeletal muscle GLUT4 protein in fructose-fed rats," Journal of Ethnopharmacology, vol. 123, no. 1, pp. 82-90, 2009.

[32] M.-J. Tan, J.-M. Ye, N. Turner et al., "Antidiabetic activities of triterpenoids isolated from bitter melon associated with activation of the AMPK pathway," Chemistry \& Biology, vol. 15, no. 3, pp. 263-273, 2008.

[33] C. C. Shih, J. B. Wu, J. Y. Jian, C. H. Lin, and H. Y. Ho, “(-)Epicatechin-3-O- $\beta$-d-allopyranoside from Davallia formosana, prevents diabetes and hyperlipidemia by regulation of glucose transporter 4 and AMP-activated protein kinase phosphorylation in high-fat-fed mice," International Journal of Molecular Sciences, vol. 16, no. 10, pp. 24983-25001, 2015.

[34] C.-C. Shih, J.-L. Ciou, C.-H. Lin, J.-B. Wu, and H.-Y. Ho, “Cell suspension culture of Eriobotrya japonica regulates the diabetic and hyperlipidemic signs of high-fat-fed mice," Molecules, vol. 18, no. 3, pp. 2726-2753, 2013.

[35] C.-H. Lin, Y.-H. Kuo, and C.-C. Shih, "Effects of Bofu-tsushosan on diabetes and hyperlipidemia associated with AMPactivated protein kinase and glucose transporter 4 in high-fatfed mice," International Journal of Molecular Sciences, vol. 15, no. 11, pp. 20022-20044, 2014.

[36] J.-B. Wu, Y.-H. Kuo, C.-H. Lin, H.-Y. Ho, and C.-C. Shih, "Tormentic Acid, a major component of suspension cells of Eriobotrya japonica, suppresses high-fat diet-induced diabetes and hyperlipidemia by glucose transporter 4 and amp-activated protein kinase phosphorylation," Journal of Agricultural and Food Chemistry, vol. 62, no. 44, pp. 10717-10726, 2014.

[37] C.-C. Shih, C.-H. Lin, and J.-B. Wu, "Eriobotrya japonica improves hyperlipidemia and reverses insulin resistance in high-fat-fed mice," Phytotherapy Research, vol. 24, no. 12, pp. 1769-1780, 2010.

[38] D. E. Kleiner, E. M. Brunt, M. Van Natta et al., "Design and validation of a histological scoring system for nonalcoholic fatty liver disease," Hepatology, vol. 41, no. 6, pp. 1313-1321, 2005.

[39] B. J. Atkinson, B. A. Griesel, C. D. King, M. A. Josey, and A. L. Olson, "Moderate GLUT4 overexpression improves insulin sensitivity and fasting triglyceridemia in high-fat-dietfed transgenic mice," Diabetes, vol. 62, no. 7, pp. 2249-2258, 2013.

[40] R. A. DeFronzo, E. Jacot, E. Jequier, E. Maeder, J. Wahren, and J. P. Felber, "The effect of insulin on the disposal of intravenous glucose. Results from indirect calorimetry and hepatic and femoral venous catheterization," Diabetes, vol. 30, no. 12, pp. 1000-1007, 1981.

[41] Y. Minokoshi, C. R. Kahn, and B. B. Kahn, “Tissue-specific ablation of the GLUT4 glucose transporter or the insulin receptor challenges assumptions about insulin action and glucose homeostasis," The Journal of Biological Chemistry, vol. 278, no. 36, pp. 33609-33612, 2003.

[42] D. W. Cooke and Y. M. Patel, "GLUT4 expression in 3T3-L1 adipocytes is repressed by proteasome inhibition, but not by inhibition of calpains," Molecular and Cellular Endocrinology, vol. 232, no. 1-2, pp. 37-45, 2005.

[43] T. Damci, S. Tatliagac, Z. Osar, and K. Ilkova, "Fenofibrate treatment is associated with better glycemic control and lower serum leptin and insulin levels in type 2 diabetic patients with hypertriglyceridemia," European Journal of Internal Medicine, vol. 14, no. 6, pp. 357-360, 2003.

[44] T. Nedachi and M. Kanzaki, "Regulation of glucose transporters by insulin and extracellular glucose in C2C12 myotubes," American Journal of Physiology-Endocrinology and Metabolism, vol. 291, no. 4, pp. E817-E828, 2006.

[45] G. I. Welsh, I. Hers, D. C. Berwick et al., "Role of protein kinase B in insulin-regulated glucose uptake," Biochemical Society Transactions, vol. 33, no. 2, pp. 346-349, 2005.

[46] S. Guo, "Insulin signaling, resistance, and metabolic syndrome: insights from mouse models into disease mechanisms," Journal of Endocrinology, vol. 220, no. 2, pp. T1-T23, 2014.

[47] N. Musi, M. F. Hirshman, J. Nygren et al., "Metformin increases AMP-activated protein kinase activity in skeletal muscle of subjects with type 2 diabetes," Diabetes, vol. 51, no. 7, pp. 20742081, 2002.

[48] A. Barthel and D. Schmoll, "Novel concepts in insulin regulation of hepatic gluconeogenesis," American Journal of Physiology-Endocrinology and Metabolism, vol. 285, no. 4, pp. E685-E692, 2003.

[49] B. Staels and J.-C. Fruchart, "Therapeutic roles of peroxisome proliferator-activated receptor agonists," Diabetes, vol. 54, no. 8, pp. 2460-2470, 2005.

[50] B. Staels, J. Dallongeville, J. Auwerx, K. Schoonjans, E. Leitersdorf, and J.-C. Fruchart, "Mechanism of action of fibrates on lipid and lipoprotein metabolism," Circulation, vol. 98, no. 19, pp. 2088-2093, 1998.

[51] S. Cases, S. J. Stone, P. Zhou et al., "Cloning of DGAT2, a second mammalian diacylglycerol acyltransferase, and related family members," The Journal of Biological Chemistry, vol. 276, no. 42, pp. 38870-38876, 2001.

[52] H. Shimano, N. Yahagi, M. Amemiya-Kudo et al., "Sterol regulatory element-binding protein-1 as a key transcription factor for nutritional induction of lipogenic enzyme genes," The Journal of Biological Chemistry, vol. 274, no. 50, pp. 3583235839, 1999.

[53] A. Xu, A. W. K. Tso, B. M. Y. Cheung et al., "Circulating adipocyte-fatty acid binding protein levels predict the development of the metabolic syndrome: a 5-year prospective study," Circulation, vol. 115, no. 12, pp. 1537-1543, 2007.

[54] S. J. Wakil, "Fatty acid synthase, a proficient multifunctional enzyme," Biochemistry, vol. 28, no. 11, pp. 4523-4530, 1989.

[55] H. Shimano, I. Shimomura, R. E. Hammer et al., "Elevated levels of SREBP-2 and cholesterol synthesis in livers of mice homozygous for a targeted disruption of the SREBP-1 gene," The Journal of Clinical Investigation, vol. 100, no. 8, pp. 2115-2124, 1997.

[56] S. Kersten, "Peroxisome proliferator activated receptors and obesity," European Journal of Pharmacology, vol. 440, no. 2-3, pp. 223-234, 2002.

[57] R. Saladin, L. Fajas, S. Dana, Y.-D. Halvorsen, J. Auwerx, and M. Briggs, "Differential regulation of peroxisome proliferator activated receptor $\gamma 1$ (PPAR $\gamma 1)$ and PPAR $\gamma 2$ messenger RNA expression in the early stages of adipogenesis," Cell Growth and Differentiation, vol. 10, no. 1, pp. 43-48, 1999.

[58] K. Hotta, T. Funahashi, Y. Arita et al., "Plasma concentrations of a novel, adipose-specific protein, adiponectin, in type 2 diabetic patients," Arteriosclerosis, Thrombosis, and Vascular Biology, vol. 20, no. 6, pp. 1595-1599, 2000. 
[59] O. Tschritter, A. Fritsche, C. Thamer et al., "Plasma adiponectin concentrations predict insulin sensitivity of both glucose and lipid metabolism," Diabetes, vol. 52, no. 2, pp. 239-243, 2003.

[60] K. R. Segal, M. Landt, and S. Klein, "Relationship between insulin sensitivity and plasma leptin concentration in lean and obese men," Diabetes, vol. 45, no. 3, pp. 988-991, 1996.

[61] S. Lin, T. C. Thomas, L. H. Storlien, and X. F. Huang, "Development of high fat diet-induced obesity and leptin resistance in C57Bl/6J mice," International Journal of Obesity, vol. 24, no. 5, pp. 639-646, 2000.

[62] X. Wu, H. Motoshima, K. Mahadev, T. J. Stalker, R. Scalia, and B. J. Goldstein, "Involvement of AMP-activated protein kinase in glucose uptake stimulated by the globular domain of adiponectin in primary rat adipocytes," Diabetes, vol. 52 , no. 6 , pp. 1355-1363, 2003.

[63] T. Yamauchi, J. Kamon, Y. Minokoshi et al., "Adiponectin stimulates glucose utilization and fatty-acid oxidation by activating AMP-activated protein kinase," Nature Medicine, vol. 8, no. 11, pp. 1288-1295, 2002.

[64] Y. Minokoshi, Y.-B. Kim, O. D. Peroni et al., "Leptin stimulates fatty-acid oxidation by activating AMP-activated protein kinase," Nature, vol. 415, no. 6869, pp. 339-343, 2002. 


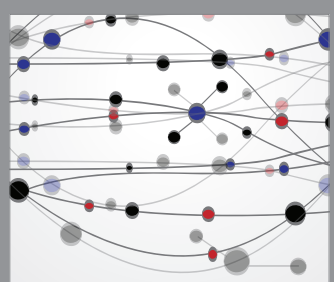

The Scientific World Journal
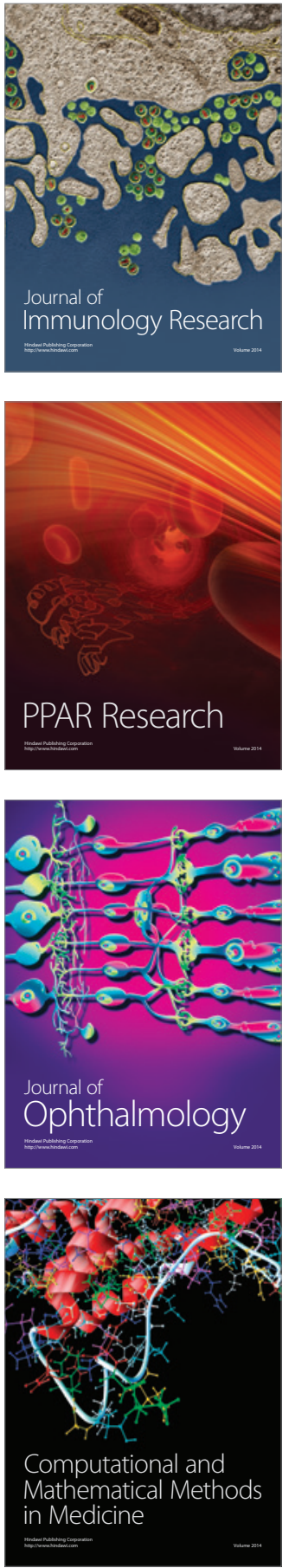

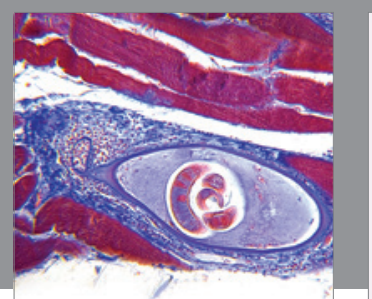

Gastroenterology Research and Practice

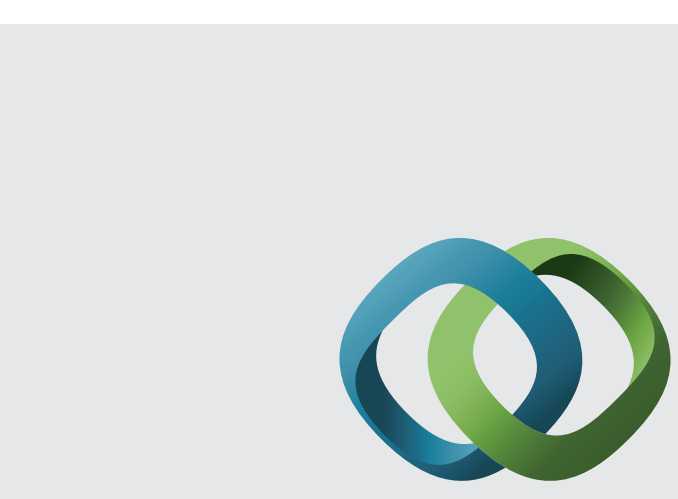

\section{Hindawi}

Submit your manuscripts at

http://www.hindawi.com
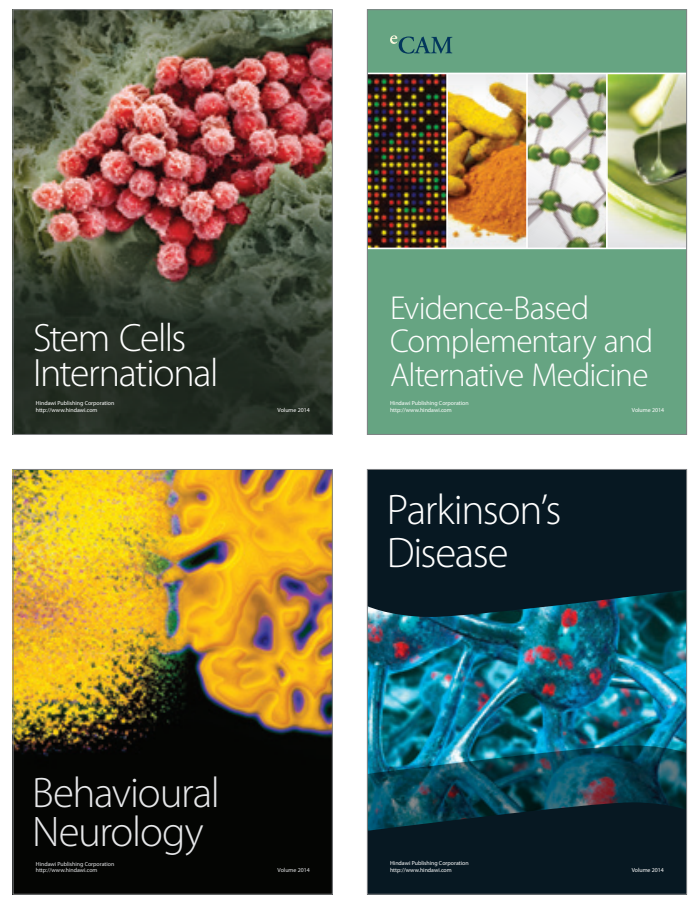
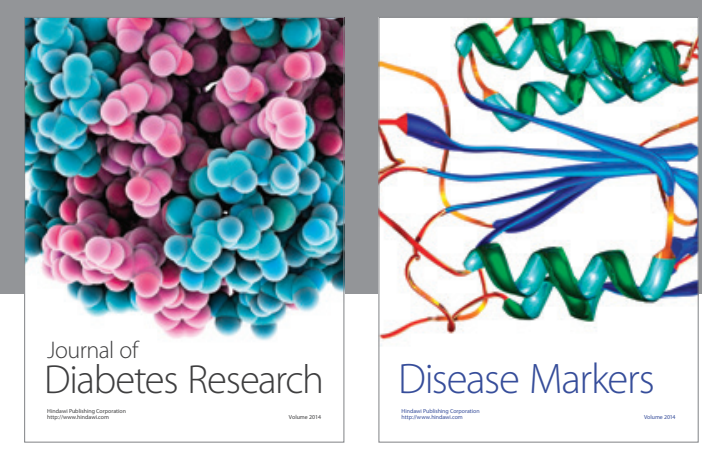

Disease Markers
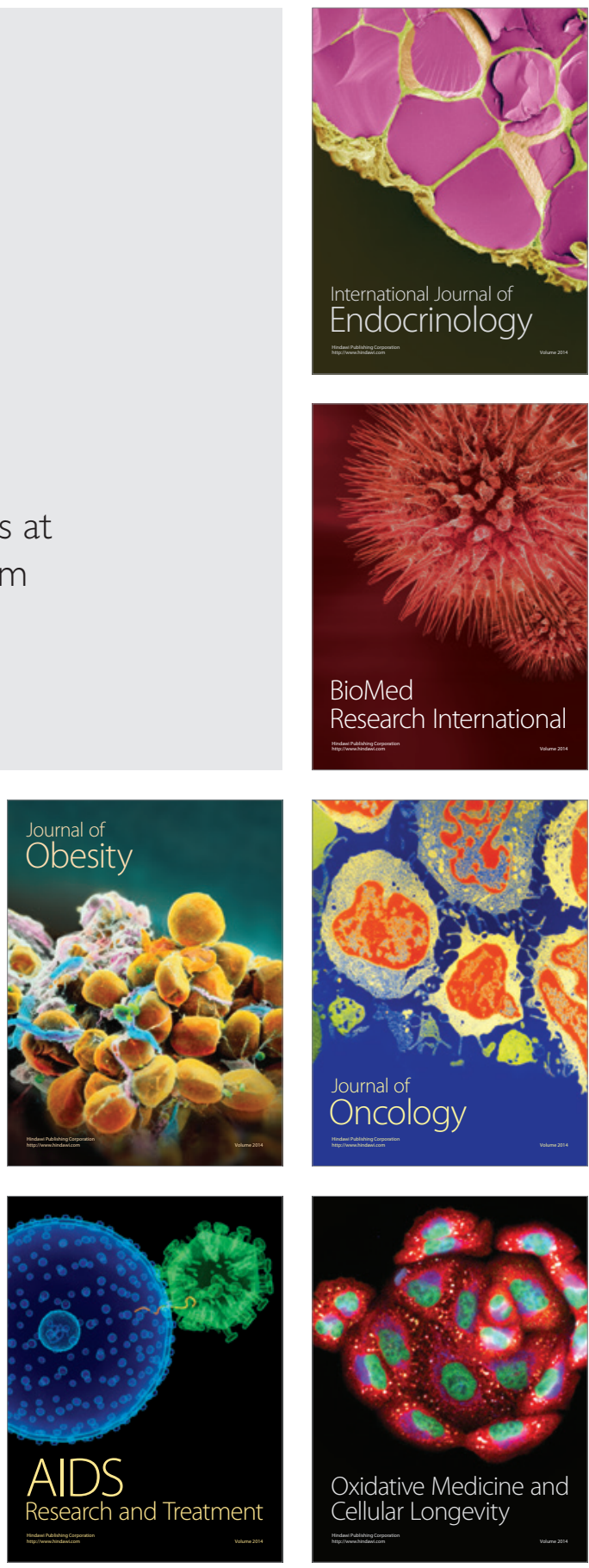